\title{
The Dynamics of DAX Implied Volatilities
}

\author{
Reinhold Hafner, Martin Wallmeier*
}

December 2000

\begin{abstract}
On the basis of transaction data, this paper analyzes the strike profile of implied volatilities of German DAX options for a time to expiration of 45 days. Beside the $\mathrm{S} \& \mathrm{P}$ option contract, the DAX option is one of the most heavily traded stock index options in the world. Using WLS spline regressions over the sample period from 1995 to 1999, we estimate a time series of smile characteristics, which we then try to attribute to economic fundamentals. Their choice is motivated by common theoretical explanations of the smile. The strike pattern almost exclusively appears as a "skew" rather than a "smile". We find that the dynamics of the smile profile can be accurately modelled by a stationary $\operatorname{AR}(1)$ process. Market uncertainty, measured by volatility of volatility, and liquidity effects seem to play an important role in determining the pattern of DAX implied volatilities across exercise prices.
\end{abstract}

JEL classification: G10; G12; G13

Keywords: Implied Volatility; DAX options; Smile; Option valuation

\section{Introduction}

During the last two decades the market for contingent claims has experienced rapid growth and many innovative product creations. For valuing these instruments the Black-

${ }^{*}$ Dipl.-Kfm. Reinhold Hafner, Financial Engineer, RiskLab GmbH, Arabellastr. 4, D-81925 Munich, E-mail: hafner@risklab.de

Dr. Martin Wallmeier, Department of Finance and Banking, University of Augsburg, Universitaetsstrasse 2, D-86135 Augsburg, E-mail: Martin.Wallmeier@WiSo.Uni-Augsburg.de 
Scholes (1973) model is often applied as a starting point. It assumes that the underlying asset is traded on a frictionless market and its price follows a geometric Brownian motion with constant volatility. If this could be regarded as a valid description of reality, then all options on the same asset should provide the same implied volatility.

As a matter of fact, the Black-Scholes conditions will never hold exactly. For example, jumps in asset prices occur, volatility varies over time and trading activity incurs transaction costs. Therefore, practitioners commonly use different volatilities for different strike prices and maturities in order to take account of deviations from the Black-Scholes assumptions. ${ }^{1}$ Consequently, the implied volatility of an option is not necessarily equal to the expected volatility of the underlying asset's rate of return. It rather also reflects determinants of the option's value that are neglected in the Black-Scholes formula. The implied volatility structure is just a convenient way of illustrating discrepancies between market and Black-Scholes prices (see, e.g., Mayhew, 1995, p.14).

Following the first empirical studies prior to the October 1987 crash, which found higher S\&P 500-implied volatilities for deep in- and out-of-the-money options, the relationship between implied volatilities and exercise prices is commonly designated as a "smile" pattern. In this paper, if not stated otherwise, the term "smile" is used as a general expression for the shape of the implied volatility pattern across exercise prices. It also covers a "skew" or "sneer", characterized by monotonically decreasing implied volatilities when the exercise price rises relative to the index level.

Understanding the characteristics and determinants of the smile pattern is important for pricing and hedging options. This is particularly relevant for instruments that provide pure exposure to volatility alone, such as volatility swaps (Demeterfi et al., 1999). The implied volatility profile extracted from liquid standard options might be transferred to illiquid exotic options. Here the pricing impact of the smile is often considerable (see, e.g. Taleb, 1997).

In the US, the literal smile profile observed before the market crash in $1987^{2}$ turned into a monotonically decreasing function afterwards. The rate of decrease is lower for options with longer time to maturity. In a recent empirical study Dumas/Fleming/Whaley (1998) conclude that the volatility profile is not stable through time. As far as S\&P 500 options are concerned, implied binomial or trinomial trees, developed by Derman/Kani

1 Hull (1997) denotes this practice as applying "tricks of trade" (p. 502).

2 See Galai (1983), Rubinstein (1985), Sheikh (1991), Heynen (1994). 
(1994a,1994b), Dupire (1994) and Rubinstein (1994), turned out to be unreliable and not really useful for valuation and risk management. Which factors in detail are responsible for changes in the smile pattern, is still an unresolved question. ${ }^{3}$

The empirical evidence from options markets outside the US tends to support a true smile profile, at least for short maturities. ${ }^{4}$ For example, Pena/Rubio/Serna (1999) find a consistent smile pattern in Spanish IBEX-35 index options throughout the sample period from January 1994 to April 1996. They conclude that particularly transaction costs and market uncertainty play a key role in explaining the dynamcis of the smile pattern. At the German market Ripper/Günzel (1997) analyze the implied volatility surface of DAX options using settlement prices over the years 1995 and 1996. They estimate only one surface for the complete sample period and thus implicitly assume that the smile profile and the term structure of implied volatilities are stable throughout the two years under study. For short-lived options Ripper/Günzel report a U-shaped profile across exercise prices, whereas options with a longer time to maturity of up to three months show an almost linear decrease of implied volatilities when the strike rises. Similar to the findings in the US, the rate of decrease is negatively related to the time to expiration.

The objectives of this paper are twofold. First of all we aim at characterizing the profile of DAX option implied volatilites for a period ranging from 1995 to $1999 .{ }^{5}$ With an average daily trading volume of 153,808 contracts as of November 1999, the DAX option (ODAX) is the most liquid Eurex index contract and ranks among the top index options contracts in the world. Secondly, we try to evaluate the explanatory power of variables which represent potential determinants of changes in the smile pattern. ${ }^{6}$ In

3 For a more comprehensive overview over empirical research to test the Black-Scholes model see Hull (1997), p. $507 \mathrm{ff}$.

4 See, e.g., Gemmill (1986) for British options and Kemna (1989) for Dutch options.

5 Tompkins (1999) estimates the smile profile of DAX options for the period from 1992 to 1996 using standardised implied volatilities. Hermann (1997) calculates implied volatilities for DAX options from 1992 to 1997. Yet, in contrast to our study Hermann focuses on nonparametric valuation models. The implied volatilities are only reported as yearly averages of moneyness and time to maturity classes (p. 186 f.). Implied Distributions of DAX options for the first half of 1994 are analyzed by Neumann/Schlag (1996).

${ }^{6}$ In related work, Skiadopoulos/Hodges/Clewlow (1989), Alexander (2000) and Fengler/Härdle (2000), use a principal component approach to analyze the dynamics of the smile pattern in stock index options. 
contrast to Ripper/Günzel (1997) this study is based on all call and put prices. Each day we generate a new estimate of the strike pattern of implied volatilities. This results in a time series of smile characteristics which we then try to attribute to the selected determinants.

Many recent articles deal with valuation models relaxing the Black-Scholes conditions. They usually focus on only one assumption, such as a constant volatility, which is supposed to cause the observed pricing biases. In contrast to this popular approach we try to detect the relative importance of various deviations from the Black-Scholes assumptions in the first step. This done, the factors in question could be useful in developing a pricing model.

The paper is organized as follows. Section 2 reviews theoretical explanations of the smile pattern. These form the basis of the choice of potential smile determinants. Section 3 presents the empirical analysis of the smile profile of German DAX options. Finally, we try to explain its time variations in Section 4. The paper concludes with a brief summary.

\section{Theoretical Explanations for the Strike Pattern of Implied Volatility}

In general, smile patterns may be either due to market imperfections or to deviations of the underlying asset's price process from lognormality. Empirical research on stock returns has accumulated convincing evidence for fat-tailed distributions, i.e. extremely low or high returns have greater probability than assigned by the normal distribution (leptokurtosis). ${ }^{7}$ Moreover, the underlying asset distribution often turns out to be asymmetric. If it is positively skewed, there is more probability mass on the right side of the distribution than on the left, and vice versa. Three explanations for these distributional properties have been offered (see, e.g., Gemmill, 1993, p. 113). In the first approach the volatility is assumed to vary over time, either deterministically or stochastically. Derman/Kani (1994a, 1994b), Dupire (1994) and Rubinstein (1994) were the first to model volatility as a deterministic function of time and stock price. Their work has subse-

7 See, e.g., Campbell/Lo/MacKinlay (1997), p. 17, for the US and Eberlein/Keller/Prause (1998) for Germany. 
quently been extended by Andersen/Brotherton-Ratcliffe (1998), Jackwerth (1997), and Chriss (1996), among others. The unknown volatility function can be fitted to observed option prices to obtain an implied price process for the underlying asset. The validity of this approach depends on whether the implied process accurately matches the true price evolution.

The stochastic volatility approach, suggested by Hull/White (1987), Heston (1993), Stein/Stein (1991) and others, assumes that volatility itself follows a stochastic process. This process can be correlated with the stock price. Different correlation coefficients will result in different probability distributions and smile patterns. If volatility is uncorrelated with the stock price, a true smile occurs whose degree depends on the other parameters of the stochastic volatility model, especially the volatility of volatility. A negative correlation coefficient spreads the left tail of the distribution and thus produces a skew pattern. A positive correlation coefficient has the opposite effect, i.e. it increases the probability of high returns. A problem of stochastic volatility models is that unrealistically high parameters are required in order to generate volatility smiles that are consistent with those observed in option prices with short times to maturity (see, e.g., Andersen/Andreasen, 1999, p. 3; Das/Sundaram, 1999, p. 5). This is not the case for long times to expiration. Another explanation for the dependence of volatility from the stock price refers to the leverage effect. A lower stock price brings about a higher leverage ratio producing an increase in stock return volatility, and vice versa. Yet, in a study on the S\&P 100 (OEX) index, Figlewki/Wang (2000) find a strong leverage effect associated only with falling stock prices. They conclude that the variations of volatility have litte direct connection to firm leverage.

The second explanation for implied volatility patterns refers to jumps in the asset price process (e.g. Bates, 1996; Trautmann/Beinert, 1999). When jumps occur, the price process is no longer continuous. Jumps have proved to be particularly useful for modelling the crash risk, which has attained considerable attention since the stock market crash of October 1987. It is often argued that the increased sensitivity of market participants to the crash risk has contributed to the skew pattern in S\&P options prevailing since 1987. Whereas the effect of stochastic volatility increases with longer time to maturity, the impact of jumps diminishes. This is due to the fact that in long time periods positive and negative jumps compensate each other. Therefore, jumps seem especially suitable for modeling the steep implied volatility smile for short maturities.

Finally, it is possible that prices move continuously but not according to a geometric 
Brownian motion. The true underlying distribution may thus be characterized by fat tails and skewness, even if the volatility is constant and jumps do not occur. For example, Eberlein/Keller/Prause (1998) propose to describe the terminal stock price using a hyperbolic distribution. Analyzing five German stocks, the authors find that the hyperbolic model accurately fits the empirically observed returns.

Market frictions are another explanation for the smile pattern. Transaction costs, illiquidity and other trading restrictions imply that a single arbitrage-free option price no longer exists. Instead, there is a band of feasible prices. ${ }^{8}$ Since arbitrage is no longer sufficient to derive a definite option price, Longstaff (1995) proposes an "unrestricted Black-Scholes model", which does not impose the martingale restriction. ${ }^{9}$ In his study of S\&P 100 index options the suggested specification is able to neutralize the pricing bias with respect to the strike profile. Longstaff concludes "that transaction costs and liquidity effects play a major role in the valuation of index options" (p. 1093).

McMillan (1996) argues that the crash of 1987 lessened the supply of put option sellers, whereas at the same time fund managers showed a higher demand for out-of-the-money puts. Because hedging the risk exposure of written out-of-the-money puts turned out to be expensive, higher prices for out-of-the-money puts were charged. This could partly explain the observed skew pattern (see also Cochrane/Saá-Requejo, 1996).

It is generally acknowledged that the influences are interrelated, and no single explanation completely captures all empirical biases in implied volatilities.

\section{Data}

In 1990 the official German derivatives market, Deutsche Terminbörse (DTB), was founded. With the merger of DTB, now Eurex Deutschland, with the Swiss Options and futures exchange SOFFEX in 1998, Eurex was created. From the very beginning the market experienced rapid growth and is now the leading derivatives exchange world-

\footnotetext{
8 Yet, Constantinides (1996) points out that transaction costs cannot fully explain the extent of the volatility smile. Figlewski (1989a, 1989b) examined the effects of transaction costs by simulating a large number of price paths and found that they could be a major element in the divergences of implied volatilities across strike prices.

9 For an empirical test of this model on the German DAX options market, see Neumann/Schlag (1996).
} 
wide, with an average daily trading volume of 1,668,252 contracts as of November 1999 (see Deutsche Börse, 2000a).

Our database contains all reported transactions of options and futures on the German stock index, DAX, traded on the DTB/Eurex over the period from January 1995 to October 1999. ${ }^{10}$ The underlying of the option, the DAX index, comprises the 30 largest and most actively traded German companies that are listed at the Frankfurt Stock Exchange (see Deutsche Börse, 1999a). The DAX is a capital-weighted performance index, i.e. dividends are reinvested. DAX options are cash settled European-Style options which expire on the third Friday of the contract month (see in the following Deutsche Börse, 2000b, pp. 56-59). At any point in time eight option maturities with lifetimes of up to two years are available: the three nearest calendar months, the three following months of the cycle March-June-September-December and the two following months of the cycle June-December. The minimum price movement is 0.1 of an index point. The futures contract on the DAX index is clearly associated with the option contract, nevertheless, some differences can be noted: the minimum price movement amounts to half of an index point and the expiry months are only the three nearest months within the cycle March-June-September-December. Trading hours changed several times during our sample period, but both products were traded at least from 9:30 a.m. to 4:00 p.m. Presently, trading takes place from 8:50 a.m. to 5:30 p.m.

To compute the implied volatility for each options trade, we apply the standard BlackScholes (1973) option pricing formula. The Black (1976) model, which could be regarded as an alternative, presumes the existence of a liquid futures contract for each option's maturity. This condition is not met at the German futures market.

Apart from the option price and the strike, three parameters are required to compute the implied volatilities: the time to expiration, the risk-free rate and the level of the underlying index. Let $t$ denote the trading day and $T_{O}$ the option's expiration date. The time to expiration $\left(T_{O}-t\right)$ is measured in calendar days. ${ }^{11,12}$ Daily series of $1,3,6$, and 12 months DM-LIBOR rates for the period from 1995 to 1998 and EURIBOR rates for 1999 serve as riskless interest rates $r$. The $\left(T_{O}-t\right)$-period interest rate is obtained by

\footnotetext{
$\overline{10}$ We are grateful to Eurex Deutschland for providing us with these data.

11 It is uncertain, whether volatility is related to trading or calendar days. The difference between calendar and trading days, expressed as a fraction of one year, is small except for very short-term options (see e.g. Hull, 1997, p. 249). These are not considered in this paper.

12 In the calculations the time to maturity is measured as a proportion of 365 days per year.
} 
linear interpolation between the available rates enclosing $\left(T_{O}-t\right)$. The resulting value is then converted to a continously compounded rate. ${ }^{13}$

Let $n(n=1, \ldots, N)$ be the trading minute of an options transaction. ${ }^{14}$ The underlying index $S_{t, n}$ on day $t$ at minute $n$ is derived from the current price $F_{t, n}$ of the futures contract most actively traded on that day. The maturity of this contract, which is normally the nearest available, is denoted by $T_{F}$. The value $F_{t, n}\left(T_{F}\right)$ corresponds to the average transaction price observed in the $T_{F}$-futures contract in minute $n$ on day $t$. To obtain the corresponding index level we solve the theoretical futures pricing model (see e.g. Hull, 1997, p. 51) $)^{15}$

$$
F_{t, n}\left(T_{F}\right)=S_{t, n} e^{r\left(T_{\mathrm{F}}-t\right)}
$$

for $S_{t, n}$. If no future is traded at minute $n$, we exclude all options transactions that took place in this minute from our database. This procedure ensures simultaneous options and underlying prices, i.e. their respective time stamps diverge by not more than one minute.

For an option expiring in $T_{O}$, Moneyness $M$ is defined as

$$
M=M_{t, n}(X)=\frac{X}{F_{t, n}\left(T_{O}\right)},
$$

where $F_{t, n}\left(T_{O}\right)$ is the theoretical $T_{O}$-futures price computed with (1) for a given $S_{t, n}$, and $X$ denotes the strike price of the option. ${ }^{16}$ An option is said to be at-the-money, if $M=1$. A call (put) is said to be in-the-money (out-of-the-money) for $M<1$ and out-of-the-money (in-the-money) for $M>1$.

Put-call-parity requires that the implied call volatilities do not systematically deviate from the implied put volatilities with the same degree of moneyness. However, on a number of trading days a scatterplot as shown in Figure 1 (left graph) was observed. Call and put implied volatilities are symbolized by crosses and squares, respectively.

${ }^{13}$ The riskless rate $r$ is dependent on day $t$ and the investment horizon $T$. For ease of exposition, we suppress these indices.

${ }^{14}$ Since trading hours changed through time, $N$ is time-dependent. To keep notation simple, we suppress the time index.

${ }^{15}$ Using the futures-based implied index level rather than the reported index level as the underlying price has also been suggested in a study for the S\&P 500 options market by Jackwerth/Rubinstein (1995), p. 9.

${ }^{16}$ For a motiviation to define moneyness with respect to the forward price rather than the spot price, see Natenberg (1994), pp. 106-110. 

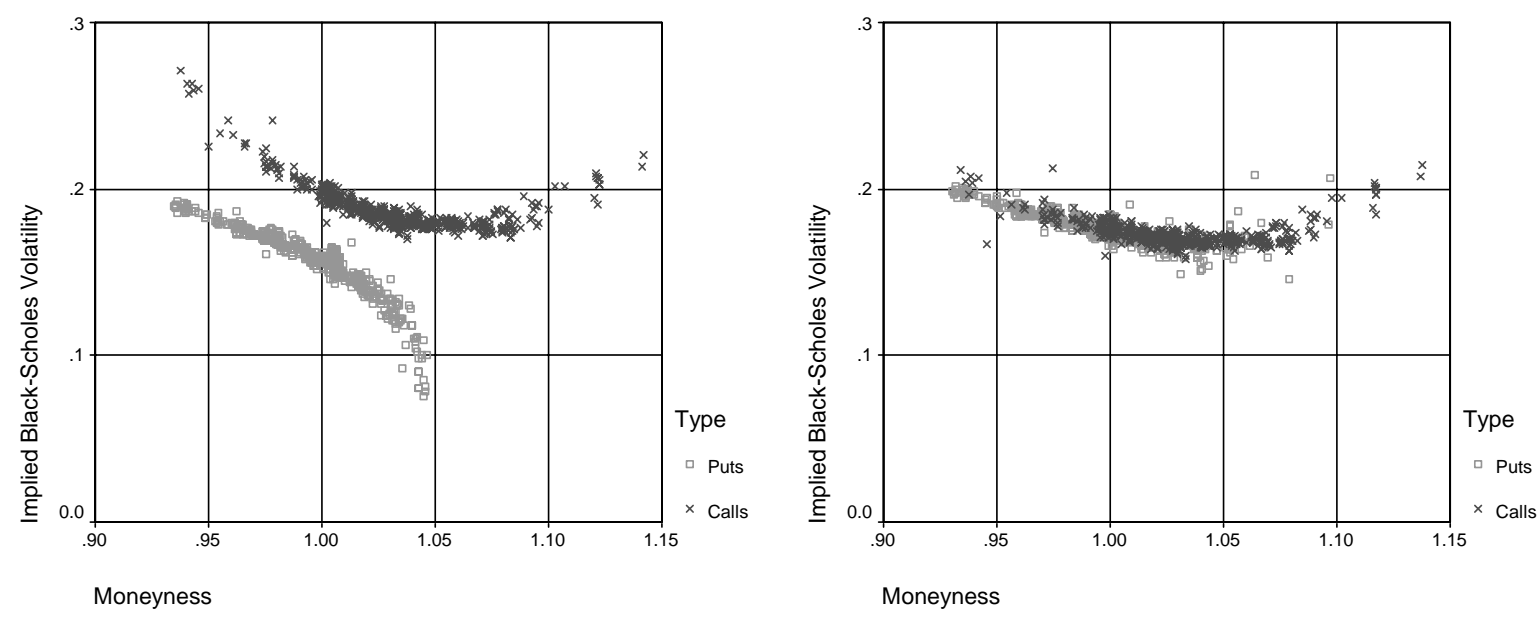

Figure 1: Left graph: implied call and put volatilities for different degrees of moneyness on March 27, 1995 (time to maturity: 25 calendar days). Right graph: implied volatilities after increasing the underlying index level by approximately 8 points.

The systematic differences apparent from Figure 1 (left graph) can be traced back to a biased index level caused by dividend payments. The DAX index calculation rests on the assumption that cash dividends are reinvested after deduction of the corporate income tax for distributed gains from the gross dividend $D I V$. This tax rate $s$ currently amounts to $30 \%$. If the marginal investor's tax rate $s_{m}$ is smaller than $s$, he receives an extra dividend of $\Delta D I V=\left(s-s_{m}\right) D I V .{ }^{17}$ In the following, this is referred to as the "difference dividend". Since the value of the dividend payment to the investors right before distribution is higher than the reinvestment amount after fictitious taxes, the continuously updated DAX falls by an amount of $\triangle D I V$ on an ex-dividend day. If $s_{m}>s$, the opposite holds. As a consequence, the difference dividend has the same effect as an ordinary dividend in the case of unprotected options and futures.

In the following we assume that dividends are sure payments. Letting $\Delta D I V_{t, T}$ denote the time $T$ terminal value of the difference dividend incurred between $t$ and $T$, we get a modified version of our futures pricing formula (1):

$$
F_{t, n}\left(T_{F}\right)=S_{t, n} e^{r\left(T_{\mathrm{F}}-t\right)}-\Delta D I V_{t, T_{\mathrm{F}}}
$$

\footnotetext{
$\overline{17}$ Ultimately, distributed gains are only subjected to the personal income tax of the owners. This is achieved by the German "Körperschaftsteuer-Anrechnungsverfahren". For a thorough analysis of the influence of cash dividends on the pricing of DAX futures see Röder (1994), p. $86 \mathrm{ff}$.
} 
or equivalently

$$
S_{t, n}=F_{t, n}\left(T_{F}\right) e^{-r\left(T_{\mathrm{F}}-t\right)}+\Delta D I V_{t, T_{\mathrm{F}}} e^{-r\left(T_{\mathrm{F}}-t\right)} .
$$

The difference dividend does not only have an impact on the valuation of DAX futures, but also influences the valuation of DAX options and the form of the put-call-parity. The modified put-call-parity is given by the equation:

$$
C_{t, n}\left(T_{O}\right)-P_{t, n}\left(T_{O}\right)=S_{t, n}-\Delta D I V_{t, T_{\mathrm{O}}} e^{-r\left(T_{\mathrm{O}}-t\right)}-X e^{-r\left(T_{\mathrm{O}}-t\right)}
$$

or, combining equations (3) and (4):

$$
C_{t, n}\left(T_{O}\right)-P_{t, n}\left(T_{O}\right)=F_{t, n}\left(T_{F}\right) e^{-r\left(T_{\mathrm{F}}-t\right)}+\Delta D I V_{t, T_{\mathrm{F}}, T_{\mathrm{O}}}-X e^{-r\left(T_{\mathrm{O}}-t\right)},
$$

where $C_{t, n}\left(T_{O}\right)$ denotes the price of a DAX call with strike price $X$ and maturity $T_{O}$ on day $t$ at minute $n, P_{t, n}\left(T_{O}\right)$ is the price of the corresponding put and $\Delta D I V_{t, T_{F}, T_{\mathrm{O}}}$ is defined by

$$
\Delta D I V_{t, T_{\mathrm{F}}, T_{\mathrm{O}}}:=\Delta D I V_{t, T_{\mathrm{F}}} e^{-r\left(T_{\mathrm{F}}-t\right)}-\Delta D I V_{t, T_{\mathrm{O}}} e^{-r\left(T_{\mathrm{O}}-t\right)}
$$

Let $\sigma_{\text {imp }, t, n}^{\text {Call }}\left(S_{t, n}, T_{O}\right)$ denote the implied call and $\sigma_{i m p, t, n}^{\text {Put }}\left(S_{t, n}, T_{O}\right)$ the implied put volatility of an option trade. Only if the underlying price in the implied volatility calculation is set to $\widetilde{S}_{t, n}:=S_{t, n}-\Delta D I V_{t, T_{\mathrm{O}}} e^{-r\left(T_{\mathrm{O}}-t\right)}$, put-call-parity implies that $\sigma_{\text {imp }, t, n}^{\text {Call }}\left(S_{t, n}, T_{O}\right)=$ $\sigma_{i m p, t, n}^{P u t}\left(S_{t, n}, T_{O}\right)$. This corresponds to the usual treatment of dividends within the BlackScholes formula. Using (3) and (6) the adjusted underlying price $\widetilde{S}_{t, n}$ can also be written as:

$$
\widetilde{S}_{t, n}=F_{t, n}\left(T_{F}\right) e^{-r\left(T_{\mathrm{F}}-t\right)}+\Delta D I V_{t, T_{\mathrm{F}}, T_{\mathrm{O}}}
$$

Apparently, our original futures pricing model (1) yields the correct underlying price $\widetilde{S}_{t, n}$ if the option's and future's expiration coincide. In all other cases, the calculated underlying price, which was hitherto assumed to be equal to $F_{t, n}\left(T_{F}\right) e^{-r\left(T_{F}-t\right)}$, has to be adjusted according to equation (7). The adjustment amount $\Delta D I V_{t, T_{\mathrm{F}}, T_{\mathrm{O}}}$ is identical for all trades on day $t$. Whereas dividend information is publicly available, the marginal investor's tax rate is unknown. Therefore, we apply an implicit method to estimate $\Delta D I V_{t, T_{\mathrm{F}}, T_{\mathrm{O}}} \cdot{ }^{18}$ This approach relies on the assumption that put-call-parity holds. If $T_{O}=T_{F}$, the term $\Delta D I V_{t, T_{\mathrm{F}}, T_{\mathrm{O}}}$ is set to zero. Otherwise, we preselect all options with a degree of moneyness between 0.9 and 1.1 and identify pairs of puts and calls with the same strike price and the same expiry provided that they are traded in the same 5

${ }_{18}$ A similar approach is used by the Deutsche Börse within their VDAX framework (see Deutsche Börse, 1997, p. 13). 
minute interval. For each pair, an estimate $\Delta \widehat{D I V} \widehat{t}_{t, T_{\mathrm{F}}, T_{\mathrm{O}}}$ for $\Delta D I V_{t, T_{\mathrm{F}}, T_{\mathrm{O}}}$ is computed from (5). If the paired call and put options are traded in different minutes $n_{1}$ and $n_{2}$ within the 5 minute interval, the futures price in equation (5) is set equal to the average of $F_{t, n_{1}}$ and $F_{t, n_{2}}$. To avoid biases due to outliers, we do not consider $\Delta D I V_{t, T_{\mathrm{F}}, T_{\mathrm{O}}}$ values greater than 15 points. ${ }^{19}$ If the number of matched pairs on day $t$ exceeds one, we take the average of the individual adjustment amounts as final estimate of $\Delta D I V_{t, T_{\mathrm{F}}, T_{\mathrm{O}}}$. The same procedure is repeated for all option's maturities traded on day $t$. Using these estimates of $\Delta D I V_{t, T_{F}, T_{\mathrm{O}}}$ we compute the modified underlying index level according to (7) and newly calculate all implied volatilities.

An inspection of all scatterplots reveals that this implied estimation of the relevant underlying index level solves the problem of the difference dividend. For example, after increasing the unadjusted DAX index by approximately 8 index points, the left graph of Figure 1 turns into the right graph, in which call and put implied volatilities no longer systematically deviate from each other.

In a final step, we eliminate all options that violate the well-known arbitrage bounds or have implied volatilities higher than $150 \%$.

At the DAX options market, liquidity is very much concentrated in short-term options and declines exponentially with increasing time to expiration. Of the total number of 3,193,860 options, $88 \%$ expire within the next 90 calendar days. The call trades distribution across degrees of moneyness is clearly skewed to the left whereas the put trades distribution is skewed to the right. This means that out-of-the money options are traded far more frequently than in-the-money options. Since the estimation of the strike profile in Section 4 requires a sufficient variety of strike prices, we include both calls and puts in our empirical study.

\footnotetext{
19 A thorough analysis of those months where $\Delta D I V_{t, T_{F}, T_{O}}$ is supposed to be high in absolute values reveals that 15 index points can be regarded as an upper bound to $\Delta D I V_{t, T_{F}, T_{O}}$. The adjustments are highest in April and on trading days after the third Friday in March. Here the nearest option's maturities are April and May, whereas the next future expires in June. Since most DAX corporations pay dividends in May, these fall into the period between the expiration dates of option and future.
} 


\section{Characterising the Strike Profile of DAX Implied Volatilities}

\subsection{Estimation Method}

The relation between the Black-Scholes implied volatility, the exercise price and the time to maturity is supposed to vary through time. To capture these variations, we include only one trading day's data in any cross sectional analysis. The daily implied volatility surface across strike prices and times to maturity could be estimated assuming a specific function such as (see Dumas/Fleming/Whaley, 1998; Tompkins, 1999; Ané/Geman, 1999)

$$
\sigma_{i m p, t}(M, T)=a_{0 t}+a_{1 t} M+a_{2 t} M^{2}+a_{3 t}(T-t)+a_{4 t}(T-t)^{2}+a_{5 t} M(T-t) .
$$

This approach, however, rests on the a priori knowledge of the adequate functional pattern. Especially the influence of the time to maturity seems uncertain. An inappropriate modelling of this component would also distort the estimation of the strike profile. Besides, the primary goal of this paper is to explain time variations of the smile pattern as opposed to analyzing the term structure of implied volatilities. For these reasons, we do not estimate the complete surface but focus on the implied volatility pattern conditional on a fixed time to expiration. The constant time to maturity ensures that day to day fluctuations of the smile can be attributed to factors other than the expiration date.

As was documented in Section 3, the trading activity in DAX options strongly concentrates on options with less than three months time to expiration. When constructing the DAX volatility index, VDAX, the Eurex chose a time to maturity of 45 calendar days as the most typical and relevant period length. This avoids the strong fluctuations of implied volatility that typically occur close to expiry. We follow this choice and restrict our empirical analysis to the smile pattern for a given time to expiration of 45 calendar days corresponding to approximately 33 trading days.

Obviously, options with the desired time to expiration are not always available. Thus, we set up the smile pattern separately for the two neighbouring maturities. Basing on these, we approximate the relevant pattern using the linear interpolation (see, e.g., Wilmott, 1998, p. 290)

$$
\sigma_{i m p, t}^{2}\left(M, T_{0}=t+45\right)=\frac{T_{2}-T_{0}}{T_{2}-T_{1}} \sigma_{i m p, t}^{2}\left(M, T_{1}\right)+\frac{T_{0}-T_{1}}{T_{2}-T_{1}} \sigma_{i m p, t}^{2}\left(M, T_{2}\right)
$$


where $T_{0}:$ assumed (fictitious) expiration date 45 calendar days in the future

$T_{1}$ : latest available expiration date before $T_{0}$ or equal to $T_{0}$

$T_{2}$ : earliest available expiration date after $T_{0}$.

One possibility to extract the smile pattern from the daily database is to assign all records with the same expiration date to different classes according to their degree of moneyness (see, e.g., Ané/Geman, 1999; Pena/Rubio/Serna, 1999). The smile is then represented by the relationship between the moneyness classes and the groups' average implied volatilities. This approach does not require an a priori specification of a function describing the smile. Yet the class estimates might be imprecise because they are each based on only a subsample of the daily database. If there are many classes, some of them will hardly be occupied. With a small number of classes, on the other hand, options with markedly different degrees of moneyness would be combined. Because of these difficulties we estimate the smile pattern using a regression approach. This should be superior to the grouping procedure if the functional form of the relation between implied volatilities and moneyness can be rather precisely specified for the chosen time to expiration.

The strike profile of implied volatilities is often modelled by a quadratic regression of the form (see, e.g., Shimko, 1991, 1993) ${ }^{20}$

$$
\sigma_{i m p}=\beta_{0}+\beta_{1} M+\beta_{2} M^{2}+\varepsilon
$$

where $\beta_{i}, i=0,1,2$ are regression coefficients and $\varepsilon$ denotes a random disturbance (see, e.g., Ripper/Günzel, 1997). In principle, this function is able to capture a true smile as well as a skew pattern. An inspection of our data, though, reveals that this approach is biased in that it often underestimates the implied volatility of options with $M>1$. Including the variable moneyness cubed as in Tompkins (1999) does not eliminate the bias. Figures 2 to 4 illustrate typical patterns in DAX implied volatilities. Most often, the "smile" is better characterized by a "sneer" (Fig. 2), with the negative relation between implied volatility and moneyness extending clearly beyond $M=1$. Only when the call (put) is deep out-of-the-money (in-the-money) the implied volatility function forms a minimum and eventually rises slightly. The quadratic regression line in Figure 2 (dotted line) obviously does not capture this increase. A literal "smile" pattern, as shown in Figure 3, rarely occurs and is almost exclusively observed for the shorter of the

${ }^{20}$ This regression is related to a certain option's trading day $t$ and a certain time to maturity $\tau$. The indices $t$ and $\tau$ are dropped for convenience of presentation. 
times to maturity ( $\leq 45$ days) used in the interpolation. Options with the longer time to expiration ( $>45$ days) often exhibit a monotonically decreasing skew profile (Fig. 4).

To account for the asymmetry of the strike pattern of implied volatilities as apparent from Figure 2 we use a spline function with the two segments $M \leq 1$ and $M>1$. Defining the dummy variable

$$
D= \begin{cases}0, & M \leq 1 \\ 1, & M>1\end{cases}
$$

the spline function is specified as

$$
\sigma_{i m p}=\beta_{0}+\beta_{1} M+\beta_{2} M^{2}+D\left(\gamma_{0}+\gamma_{1} M+\gamma_{2} M^{2}\right)+\varepsilon,
$$

where $\beta_{i}$ and $\gamma_{i}, i=0,1,2$ are constant coefficients. To make the function continuous we require that the segments join at the threshold $M^{*}=1$, that is

$$
\gamma_{0}+\gamma_{1} 1+\gamma_{2} 1^{2}=0
$$

In addition we suppose a smooth, differentiable function. Specifically, we require that

$$
\left.\frac{d\left(\gamma_{0}+\gamma_{1} M+\gamma_{2} M^{2}\right)}{d M}\right|_{M^{*}=1}=\gamma_{1}+2 \gamma_{2} 1=0
$$

Introducing the restrictions (11) and (12) in (10) we obtain

$$
\sigma_{i m p}=\beta_{0}+\beta_{1} M+\beta_{2} M^{2}+D \gamma_{2}\left(1-2 M+M^{2}\right)+\varepsilon
$$

This regression formally differs from the conventional approach (9) in that it includes the term $D\left(1-2 M+M^{2}\right)$ as an additional explanatory variable. The estimated regression functions according to Equation (13) are shown in Figures 2 to 4 as the unbroken lines. The implied volatility of deep in-the-money calls and puts is very sensitive to changes in the index level. Since small errors in determining the appropriate index level are unavoidable, the disturbance variance of regression model (13) is supposed to increase as options go deeper in-the-money. Residual scatterplots support this presumption. Using the White-test, the null hypothesis of homoskedasticity was rejected in about $60 \%$ of all regressions. To account for the heteroskedasticity of the disturbances we apply a weighted least squares estimation assuming that the disturbance variance is proportional to the positive ratio of the option's delta and vega. ${ }^{21}$ This ratio indicates

$\overline{21}$ The delta and vega are computed using the implied volatility of the corresponding option. The delta of puts is multiplied by -1 to obtain a positive ratio. 


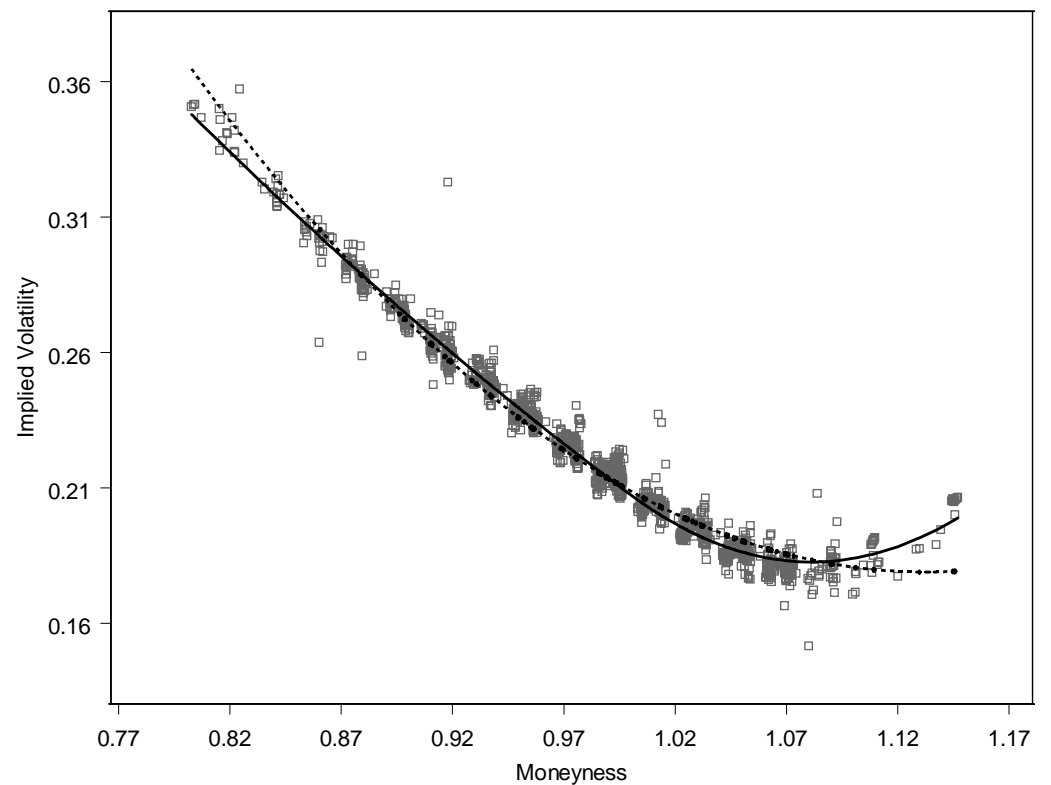

Figure 2: Scatterplot of implied volatilities across moneyness on May 21, 1999 (time to maturity: 28 calendar days). Dotted line: quadratic regression; unbroken line: WLS spline regression.

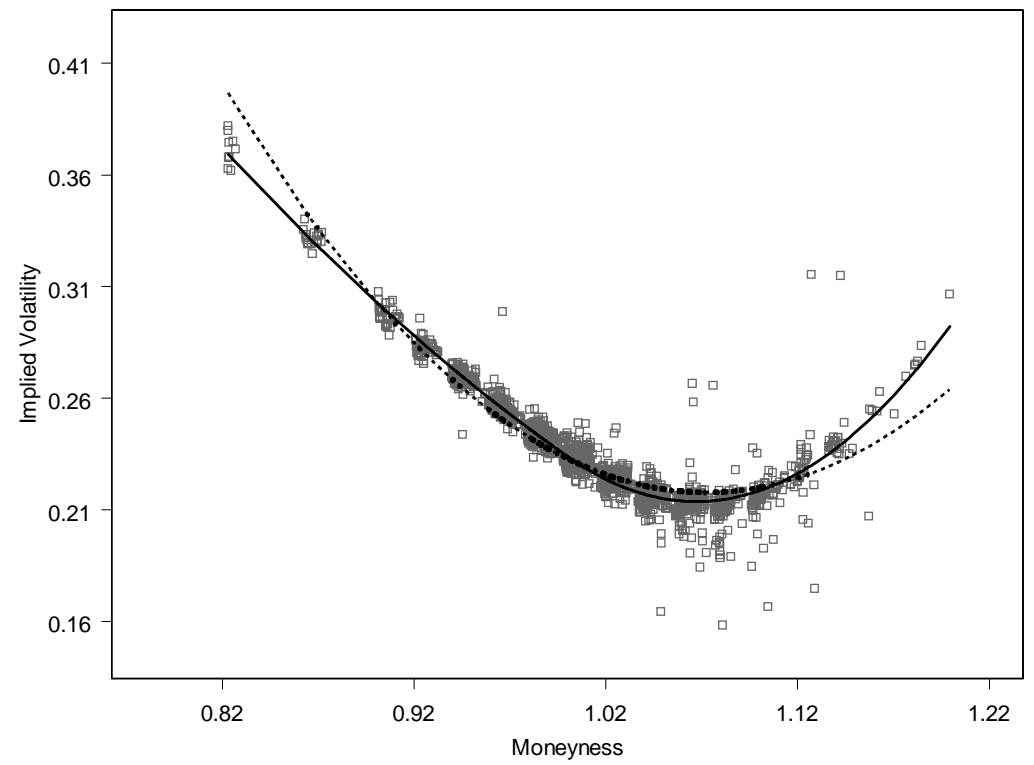

Figure 3: Scatterplot of implied volatilities versus moneyness on July 30, 1999 (time to maturity: 21 calendar days). Dotted line: quadratic regression; unbroken line: WLS spline regression. 
how an increase in the index level by one (marginal) point affects the implied volatility of an option, if its price does not change.

In view of the large number of intraday transactions it is not astonishing that some extreme deviations occur representing "off-market" implied volatilities. They can, for example, be due to a faulty and unintentional input by a market participant. In this case, the trade can be annulled if certain conditions are fulfilled. To exclude such unusual events we discard all observations corresponding to large errors of more than four standard deviations of the regression residuals where the standard deviation is computed as the square root of the weighted average squared residuals. We then repeat the estimation on the basis of the reduced sample until no further observations are discarded. This procedure is known as applying the "4-sigma-rule" (Sachs, 1972, p. 219) or "trimmed regression" (Kmenta, 1997, p. 265). We examined the impact of this exclusion of outliers and found it to be negligible in all but very few cases.

A large percentage of all traded DAX options in the period from 1995 to 1999 features a degree of moneyness between 0.8 and 1.2. We discard all observations outside this range in order to eliminate potential problems with extreme degrees of moneyness. In particular, the quadratic form of the regression can only be regarded as an acceptable model of the smile pattern within a restricted interval around the at-the-money point.

In the examples of Figures 2 to 4 the unbroken lines represent the result of the "trimmed" WLS spline regressions. In general, plotting the residuals did not reveal any remaining violations of the assumptions of the chosen regression model.

\subsection{Empirical Results}

For each day $t \in\{1, \ldots, 1211\}$ and for each of the two option's maturities $T_{1}$ and $T_{2}$ surrounding $T_{0}$ ( $=t+45$ days) we estimate a regression of implied volatility on moneyness as described in Section 4.1. The average $T_{1}$-option expires in about 30 days and the average $T_{2}$-option in about 60 days.

Across the 1211 days during the sample period the average adjusted $R^{2}$ values for the 
$T_{1^{-}}$and $T_{2}$-options are $94.09 \%$ and $95.55 \%$, respectively. ${ }^{22}$ This indicates that, using our regression model, most of the variation of implied volatilities can be attributed to a variation of the degree of moneyness. Extending our regression analysis to longer option's maturities, we find similar average $R^{2}$ values. The goodness-of-fit does not seem to depend neither on the maturity nor the liquidity of an option.

\section{VDAX Index Tracking}

Our choice of a constant time to maturity of 45 days was partly motivated by the correspondance to the volatility index VDAX. This index represents the implied volatility of at-the-money DAX options with a remaining lifetime of 45 days. It is constructed as follows: For each DAX option's maturity traded at a given point in time, the Eurex calculates a volatility subindex based on the implied volatilities of the two calls and puts with strikes nearest to the DAX futures or forward price for that maturity. The VDAX is then determined by linear interpolation between the two subindices which represent times to maturity next to 45 days (see Deutsche Börse, 1997).

By evaluating our regression functions for a moneyness equal to one we obtain estimates of at-the-money implied volatilities for the $T_{1^{-}}$and $T_{2}$ - options for each day in the sample. Employing the interpolation scheme (8), we are able to construct a volatility index SVDAX. Figure 5 shows that the SVDAX and the VDAX are almost identical although the estimation methods differ. In Figure 5, the VDAX is reduced by 8 percentage points in order to allow a distinction between both graphs. The strong correspondence between the two indices manifests itself in an almost perfect positive correlation of 0.997 within the sample period..$^{23}$

${ }^{22}$ It should be noted that in the case of a WLS regression model there exists no single generally accepted definition of $R^{2}$. The reported values are based on the non-weighted WLS regression residuals. The meaning of this $R^{2}$ is not exactly the same as in a OLS regression (for more details, see e.g. Greene, 1997, p. 509).

${ }^{23}$ The largest difference between VDAX and SVDAX was observed on August 15, 1997. A close examination of this day's data supports the correctness of SVDAX. 


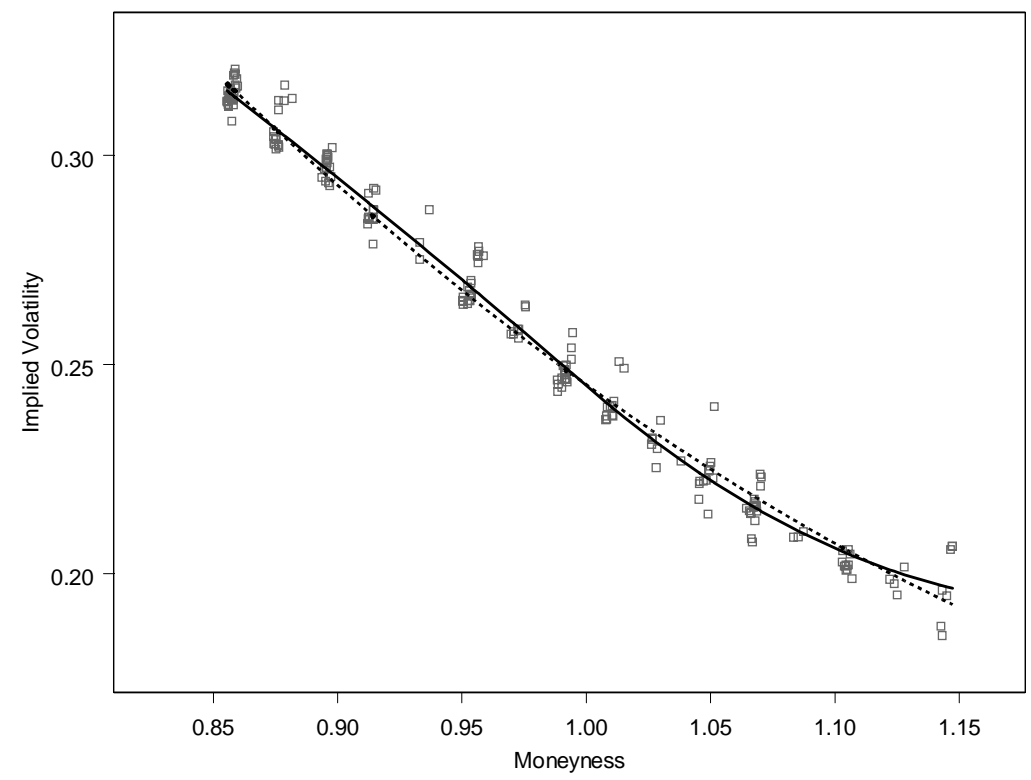

Figure 4: Scatterplot of implied volatilities across moneyness on May 20, 1999 (time to maturity: 57 calendar days). Dotted line: quadratic regression; unbroken line: WLS spline regression.

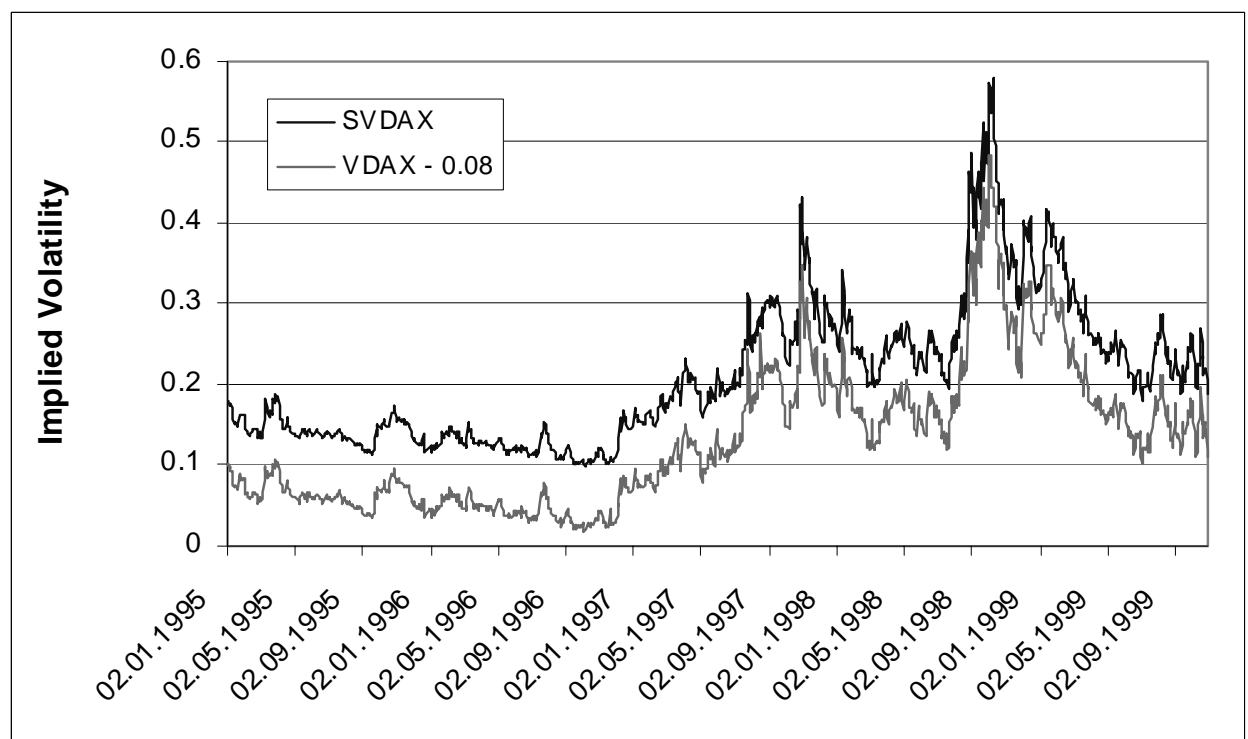

Figure 5: SVDAX and VDAX (shifted downwards by 8 percentage points) on a daily basis over the period January 1995 to October 1999. 


\section{Aver age Parameter Est imates}

Table 1 reports the average and the standard deviation of the daily coefficient estimates for each parameter and for each of the two maturities $T_{1}$ and $T_{2} \cdot{ }^{24}$ As expected, the coefficient $\widehat{\beta}_{1}$ is on average negative as opposed to the positive average slope coefficient $\overline{\widehat{\beta}}_{2}$. The asymmetry of in- and out-of-the-money implied volatilities is apparent from the positive $\bar{\gamma}_{2}$-value. The shape of the volatility smile proves to be quite different for the two option's maturities. Considering the underlying deterministic implied volatility function (smile function) $\sigma_{i m p}=\beta_{0}+\beta_{1} M+\beta_{2} M^{2}+D \gamma_{2}\left(1-2 M+M^{2}\right)$ the computation of the slope and the curvature (first and second derivative) relative to moneyness yields $\beta_{1}+2 \beta_{2} M+D \gamma_{2}(-2+2 M)$ and $2 \beta_{2}+D 2 \gamma_{2}$, respectively. The daily regression results show that in general the smile function for the $T_{1^{-}}$options is steeper and more convex than the one for the $T_{2}$ - options. The average second derivative of the $T_{1}$-maturity smile of $2.1618+D \cdot 5.372$ is significantly higher than the corresponding value of the $T_{2}$-smile, $0.5296+D \cdot 2.0968$. Due to this higher convexity, the $T_{1}$-smile function on average reaches its minimum at distinctly lower degrees of moneyness than the $T_{2}$-function. The minimum is almost always located at degrees of moneyness clearly above one, implying a pronounced skew. With regard to the three smile patterns introduced in Section 4.1, the $T_{1}$-option mostly exhibits a smile of type 1 whereas type 3 is represented by the typical pattern of $T_{2}$-maturity options. The average at-the-money implied volatility in the sample, given by $\overline{\widehat{\beta}}_{0}+\overline{\widehat{\beta}}_{1}+\overline{\widehat{\beta}}_{2}$, amounts to $20.82 \%$ for the $T_{1}$-options and $21.51 \%$ for the $T_{2}$-options. This means that on average the term structure of volatility is slightly upward sloping in this time to maturity region.

The standard deviations in Table 1 indicate that there is considerable variation in the coefficient estimates from day to day. This observation, however, cannot be taken as evidence for a strongly changing smile pattern. Distinctly different parameters of the specified smile function can produce almost identical results at degrees of moneyness near one. For example, the functions $M \rightarrow f: f(M)=1.8-2.7 M+1.1 M^{2}$ and $M \rightarrow g: g(M)=2.897-4.9 M+2.2 M^{2}$ look very similar when plotted in the interval $0.93 \leq M \leq 1.07$. The higher coefficients $\beta_{0}$ and $\beta_{2}$ of function $g$ as compared to function

24 The standard deviation is calculated as $s_{\widehat{\beta}_{i}}=\sqrt{\frac{1}{1210} \sum_{t=1}^{1211}\left(\widehat{\beta}_{i t}-\widehat{\widehat{\beta}}_{i}\right)^{2}},(i=0,1,2)$, where $\widehat{\beta}_{i t}$ is the parameter estimate of parameter $i$ on day $t$ (analogous $s \widehat{\gamma}_{2}$ ). The t-value of $\overline{\widehat{\beta}}_{i}$ is then given by $\frac{\widehat{\widehat{\beta}}_{i}}{\widehat{s}_{\beta_{i}}} \sqrt{1211}$ 


\begin{tabular}{|c|c|c|}
\hline & $T_{1}(\leq 45$ days $)$ & $T_{2}(>45$ days $)$ \\
\hline$\widehat{\widehat{\beta}}_{0}$ & 1.8133 & 0.8828 \\
$s_{\widehat{\beta}_{0}}(t-$ value $)$ & $1.3613(46.3541)$ & $0.9100(33.7593)$ \\
\hline$\widehat{\beta}_{1}$ & -2.6860 & -0.9325 \\
$s_{\widehat{\beta}_{1}}(t-$ value $)$ & $2.8391(-32.9228)$ & $1.8719(-17.3356)$ \\
\hline$\widehat{\widehat{\beta}}_{2}$ & 1.0809 & 0.2648 \\
$s_{\widehat{\beta}_{2}}(t-$ value $)$ & $1.4434(26.0598)$ & $0.9551(9.6481)$ \\
\hline $\bar{\gamma}_{2}$ & 2.6860 & 1.0484 \\
$s_{\widehat{\gamma}_{2}}(t-$ value $)$ & $2.6484(35.2935)$ & $1.9024(19.1777)$ \\
\hline
\end{tabular}

Table 1: Average, standard deviation and t-value of the daily parameter estimates over the period January 1995 to October 1999.

$f$ are to some extent offset by the lower coefficient $\beta_{1}$. Not surprisingly, the daily parameter estimates are highly correlated. ${ }^{25}$ Thus, in contrast to Pena/Rubio/Serna (1999) we do not focus on the dynamics of the single regression coefficients to analyze the dynamics of the smile pattern.

\section{Describing the dynamics of the DAX option's smile}

We use two simple measures to describe each smile pattern of DAX options with a time to expiration of 45 days. The first one, denoted by $S P 1$, is defined as the difference (the "span") between the implied volatility for moneyness 0.95 and the at-the-money implied volatility SVDAX. The second measure $S P 2$ is analogously defined as the difference between the at-the-money implied volatility SVDAX and the implied volatility for moneyness 1.05. The implied volatilities for $M=0.95$ and $M=1.05$ are generated by linear interpolation in the same way as the variable SVDAX. The variables $S P 1$ and $S P 2$ can be interpreted as indicators for the average slope of the smile function in different moneyness regions.

The moneyness boundaries of 0.95 and 1.05 were choosen such that the number of observations outside this interval always suffices to ensure an accurate estimate of the implied volatilities at the boundaries. Since on many days option trades with a degree of

${ }^{25}$ For example, the sample correlation coefficient between the time series of the coefficients $\widehat{\beta}_{1}$ and $\widehat{\beta}_{2}$ is -0.998 for both the shorter and longer times to maturity. 
moneyness greater than 1.1 or lower than 0.9 do not occur, we were not able to enlarge the chosen boundaries.

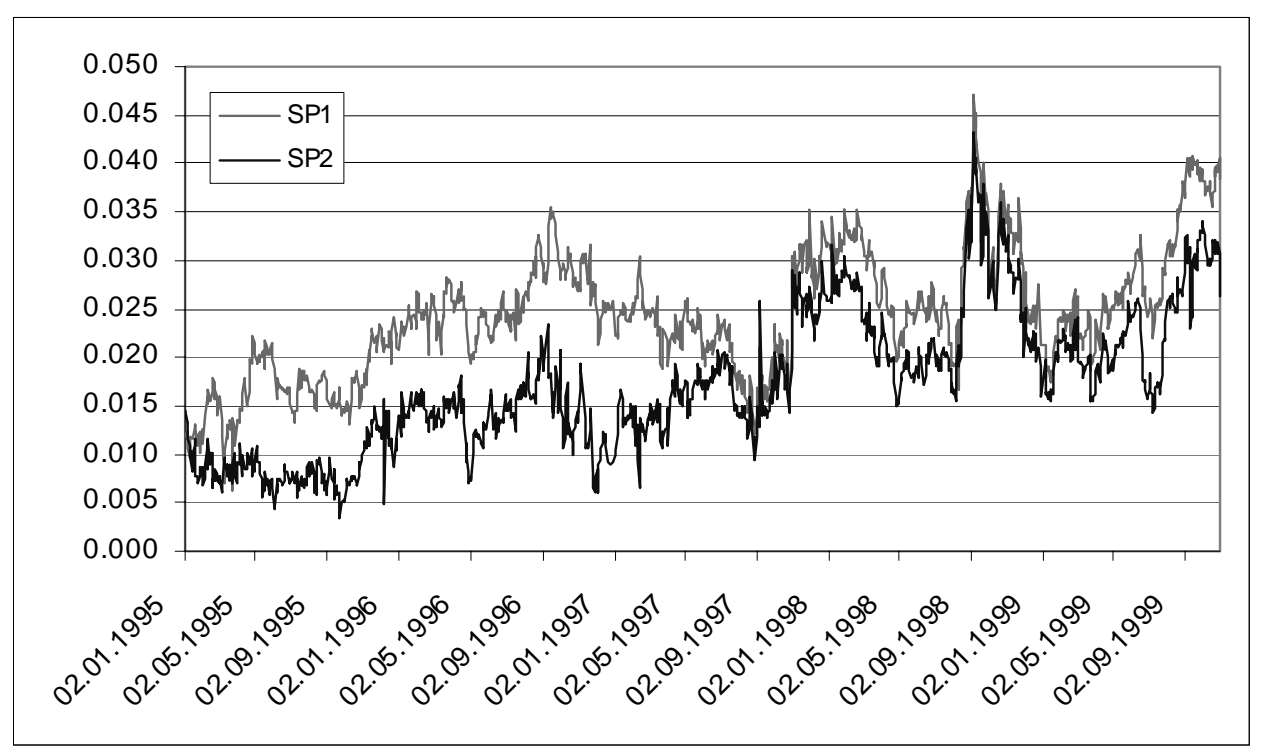

Figure 6: $S P 1$ and $S P 2$ values for the period January 1995 to October 1999.

Figure 6 plots the $S P 1$ and $S P 2$ time-series for the sample period from January 1995 to October 1999. Both time series assume only positive values. This is consistent with our previous findings that the typical smile pattern appears as a skew and not as a symmetric smile. Otherwise, SP2 would have been negative. Both $S P 1$ and $S P 2$ tend to increase within the sample period. With the exception of the first quarter of 1995 and the first half of 1997 the variables are highly correlated (correlation coefficient of 0.823 over the complete period). Owing to the curvature of the smile function, SP1 lies almost always above $S P 2$. On average, the implied volatility of DAX options with moneyness 0.95 is $2.44 \%$ higher than the at-the-money implied volatility, which in turn is $1.73 \%$ higher than the implied volatility for options with moneyness 1.05 . For the US, Zou/Derman (1999) report a slightly larger total span, $S P 1+S P 2$, of $5 \%$. The skewness of both variables is sufficiently large as that the hypothesis that they follow a normal distribution could be rejected (see the tests of normality suggested by Kmenta, 1997, p. 265). 


\title{
4.3 Robustness of Results
}

\author{
Int raday Effects
}

On the one hand, the precondition of stationarity in the regressions is best achieved by selecting data from a short time window. On the other hand, however, if the environment does not change dramatically, a larger database may improve the precision of the regression estimates. Our analysis of this tradeoff argues in favor of the second view. For example, selecting a two-hour interval from 2:00 to 4:00 p.m., often strongly reduces the range of strikes for which call and put prices are available. Therefore, we do not restrict the time window.

Certainly, new pieces of information and large intraday variations in the underlying index level may alter the shape of the smile structure. To investigate this issue we had a closer look at the three most extreme market decreases ${ }^{26}$ caused by the Asian and Russian crisis. It became apparent that the smile profile only experienced a parallel shift. The shape of the smile, however, turned out to be stable across different intraday time windows. ${ }^{27}$

The strong correspondence of the SVDAX and the VDAX, reported earlier, is another indication of the robustness of the results.

\section{Definition of Degree of Moneyness}

Natenberg (1994) and Dumas/Fleming/Whaley (1998) propose to include the time to expiration in the definition of the degree of moneyness. Given a certain relation of strike and futures price, a shorter time to maturity translates into a more extreme moneyness. In this paper, we focus on the smile pattern for a constant time to maturity. To estimate this profile we have to interpolate between the two neighbouring times to expiration. This is where the definition of moneyness might be important. Thus, we recalculated the spans $S P 1$ and SP2 using the moneyness definition of Dumas/Fleming/Whaley (1998). We found that they are almost perfectly correlated with the spans reported

\footnotetext{
26 October 28, 1997; August 21, 1998; October 1, 1998.

27 This is compatible with a model proposed by Rosenberg (2000). He separately estimates the timeinvariant smile and the stochastic process of the at-the-money implied volatility as the only relevant state variable.
} 
earlier (correlation coefficients greater than 0.995) signifying a negligible influence of the definition of the degree of moneyness in this study.

\section{A bsol ut e ver sus Rel at ive Impl ied Vol at il it ies}

Ripper/Günzel (1997) and Tompkins (1999) express all implied volatilities as multiples of the at-the-money level. These volatility factors can easily be extracted from our regression results. Standardizing volatilities relative to the level of the at-the-money option rests on the assumption that a skew should be defined as constant if all volatilities change in proportion to the level of the at-the-money option. But this is not the only acceptable definition. As long as the reasons for the existence of the smile are debatable, there is no compelling argument to decide whether the differences or the proportions of implied volatilities are relevant. We define the spans $S P 1$ and $S P 2$ as absolute differences as explained earlier. To capture the influence of the at-the-money volatility level on our spans we include the current volatility as an explanatory variable in the following Section 5 .

\section{Determinants of the Strike Profile}

\subsection{Explanatory Variables}

The following time-series regression analysis is concerned with the explanation of the dynamics of the DAX option's volatility smile. Because of the high correlation of $S P 1$ and $S P 2$, we do not differentiate beween these variables any longer. Instead, we use the total span $S P^{*}=S P 1+S P 2$ as the variable to be explained. The explanatory variables are defined as proxies for the theoretical explanations of the smile pattern summarized in Section 2.

It is important to note that under certain assumptions the smile pattern reflects the shape of the state price density (risk-neutral distribution). ${ }^{28}$ To analyze variations of the smile pattern is just another way of looking at variations of the state price density. Thus, we cannot reasonably "explain" the dynamics of the smile using moments of the riskneutral distribution. Instead we consider real-world variables as potential explanations.

\footnotetext{
28 See Breeden/Litzenberger (1978).
} 
The first group of explanatory variables characterizes the distribution of intraday returns of the underlying DAX index by means of the sample standard deviation (VOLMN), sample skewness $(S K M N)$ and sample kurtosis $(K T M N)$. More formally, dividing each trading day $t$ into $N$ periods of equal length we define the continuously compounded return in period $n(n=1, \ldots, N)$ as $R_{t, n}=\ln \left(S_{t, n} / S_{t, n-1}\right)$, where $S_{t, n}$ denotes the last futures-implied DAX index level in period $n(n=0, \ldots, N) . \operatorname{VOLMN}, S K M N$, and $K T M N$ are then given by

$$
\begin{aligned}
V O L M N_{t} & =\sqrt{\frac{1}{N-1} \sum_{n=1}^{N}\left(R_{t, n}-\widehat{\mu}_{t}^{M N}\right)^{2}} \\
S K M N_{t} & =\frac{N}{(N-1)(N-2)} \cdot \frac{\sum_{n=1}^{N}\left(R_{t, n}-\widehat{\mu}_{t}^{M N}\right)^{3}}{\left(V O L M N_{t}\right)^{3}} \\
K T M N_{t} & =\frac{N(N+1)}{(N-1)(N-2)(N-3)} \cdot \frac{\sum_{n=1}^{N}\left(R_{t, n}-\widehat{\mu}_{t}^{M N}\right)^{4}}{\left(V O L M N_{t}\right)^{4}}
\end{aligned}
$$

where

$$
\widehat{\mu}_{t}^{M N}=\frac{1}{N} \sum_{n=1}^{N} R_{t, n} .
$$

The choice of $N$ as the sampling frequency requires us to balance two opposite effects. On the one hand, in order to achieve a low sampling error a high $N$ seems desirable. On the other hand, extremely short intraday time periods give rise to the concern that market microstructure effects such as price discreteness, nonsynchronous trading or bidask bounces may induce a bias in the estimates (see, e.g., Campbell/Lo/MacKinlay, 1997, p. 83-144). Chosing an appropriate sampling frequency is largely an empirical matter. In this paper we follow the choice of Andersen et al. (1999) who use a sampling interval of 5 minutes. The fact that the three estimators are non-overlapping is advantageous for several reasons. In particular, outliers are absorbed right away, regime shifts are incorporated quickly and autocorrelation is not automatically induced in the estimator. On the other hand, non-overlapping estimators are less robust than their overlapping counterparts (see, e.g., Jacquier, 1999).

In addition to the variables $V O L M N, S K M N$, and $K T M N$, which reflect sample distribution moments for one day, we include three variables to measure the realized volatility (VOL33), skewness (SK33), and kurtosis (KT33) over the last 33 trading days. The time window of 33 days is selected to correspond with the time to expiration of the options under consideration. Denoting by $S_{t}$ the last futures-implied DAX index level on trading day $t$ and by $R_{t}=\ln \left(S_{t} / S_{t-1}\right)$ the continously compounded one day 
return, the variables are defined as

$$
\begin{aligned}
V O L 33_{t} & =\sqrt{\frac{1}{K-1} \sum_{k=1}^{K}\left(R_{t-k+1}-\widehat{\mu}_{t}^{33}\right)^{2}} \\
S K 33_{t} & =\frac{K}{(K-1)(K-2)} \cdot \frac{\sum_{k=1}^{K}\left(R_{t-k+1}-\widehat{\mu}_{t}^{33}\right)^{3}}{\left(V O L 33_{t}\right)^{3}}, \\
K T 33_{t} & =\frac{K(K+1)}{(K-1)(K-2)(K-3)} \cdot \frac{\sum_{k=1}^{K}\left(R_{t-k+1}-\widehat{\mu}_{t}^{33}\right)^{4}}{\left(V O L 33_{t}\right)^{4}}
\end{aligned}
$$

where

$$
\widehat{\mu}_{t}^{33}=\frac{1}{K} \sum_{k=1}^{K} R_{t-k+1}
$$

and $K=33 .^{29}$ As opposed to $V O L M N, S K M N$, and $K T M N$ the daily time series of VOL33, SK33, and KT33 are overlapping and thus necessarily autocorrelated. This issue is adressed in Section 5.2.

If the estimated intraday return distribution or the distribution of the daily returns in the recent past were representative of the return distributions in the future, we would expect the measures of skewness to exert a negative influence and the measures of kurtosis to exert a positive influence on the span of implied volatilities.

The next explanatory variable is a proxy for the volatility of volatility parameter of stochastic volatility models. This parameter, which measures the speed with which volatility is changing, can be interpreted as a stronger indicator of the degree of uncertainty in the market of the underlying than the volatility of the underlying itself. The smile should become more pronounced when this uncertainty rises. Our proxy $V V O L$ is defined as the volatility of the volatility returns over the last 33 trading days:

$$
V V O L_{t}=\sqrt{\frac{1}{K-1} \sum_{k=1}^{K}\left(R_{t-k+1}^{V}-\widehat{\mu}_{t}^{V}\right)^{2}}, \quad \widehat{\mu}_{t}^{V}=\frac{1}{K} \sum_{k=1}^{K} R_{t-k+1}^{V}
$$

where $K=33$ and the daily continously compounded volatility return is calculated as $R_{t}^{V}=\ln \left(V O L M N_{t} / V O L M N_{t-1}\right)$.

As was documented in Section 2, another common explanation for the smile pattern is the existence of jumps in the price process of the underlying asset. Jumps are certainly difficult to detect in discretely sampled time series. We use a very simple proxy (JUMP),

29 To calculate the values at the beginning of 1995 we also computed the futures-implied DAX index levels at the end of 1994. 
which is defined as the continously compounded overnight return of the underlying asset. This overnight jump is computed as the difference betwen the logarithm of the opening underlying price on day $t$ and the logarithm of the closing price on day $t-1$, divided by the intraday volatility of the last day $V O L M N_{t-1}$. If $J U M P$ is high (low) it implies that the overnight price change was large (small) compared with the last day's volatility. $J U M P$ can be interpreted as the standardized overnight return caused by the arrival of new information while the market was closed. We expect negative information (negative $J U M P$-value) to increase $S P^{*}$.

A related variable is $D A X R T$, which, for each trading day $t$, is defined as the continously compounded intraday return, calculated on the basis of the opening and the closing price of the futures-implied DAX on day $t$. Whereas JUMP expresses the overnight return, $D A X R T$ is the intraday return during trading hours. It is often hypothesized that negative intraday returns lead to higher at-the-money implied volatilities, and vice versa. The at-the-money volatility is in turn postulated to be positively related to the smile skewness measured by $S P^{*}$. In sum, $D A X R T$ can be interpreted as a short-term market momentum measure, which represents a potential influence of the level of implied volatilities and the shape of the smile pattern.

The stochastic volatility models lead to the conclusion that the volatility smile should also depend on the correlation between DAX returns and DAX volatility. To measure this influence we include a variable $C O R R$, defined as the correlation coefficient between the daily continously compounded volatility returns $R_{t}^{V}$ and the daily continously compounded DAX returns $R_{t}$ over the last 33 trading days.

The last explanatory variable $(P V O T M P)$ is supposed to be a proxy for market frictions. It is defined as the daily trading volume of out-of-the-money put options as a percentage of the total trading volume on the same day. All puts with a degree of moneyness lower than 0.95 are thereby considered as "out-of-the-money". As was illustrated in Section 3, out-of-the-money put options are often illiquid. Since most clients are interested in buying rather than selling out-of-the-money puts, short positions are often almost exclusively held by market makers. As a result, their options portfolio may be unbalanced forcing them to hedge dynamically by taking positions in the underlying asset. Because this causes costs and is not riskless, the market maker might demand a premium for taking short positions in out-of-the-money puts. According to this hypothesis $S P^{*}$ should be positively related to PVOTMP. We do not include out-of-the-money calls in the definition of this variable because short positions in these 
options are expected to be less strongly concentrated on market makers.

The pairwise correlations of the explanatory variables turn out to be rather small (always below 0.4). We do not include the at-the-money volatility SVDAX in the regressions, since it is highly correlated with the variable $V O L 33$.

\subsection{Stationarity and Serial Correlations}

A key assumption in the classical linear regression model is that the disturbances are uncorrelated. This is questionable in a time-series model since the disturbances might represent a number of neglected variables which move gradually over time. The consequences of serially correlated disturbances for the estimation method depend on whether the series is (covariance) stationary, i.e. whether the autocovariances are constant over time. A sufficient condition for the stationarity of the disturbances is that all variables in the regression follow a stationary process. Nonstationary variables exhibit a deterministic or stochastic time trend, corresponding to trend-stationary or difference-stationary processes (see, e.g. Maddala, 1988, p. 212 f.). The regression of one difference-stationary variable on another will very often produce a "significant" relationship, even if the two are, in fact, unrelated (Granger/Newbold, 1974). This is known as the problem of spurious regression.
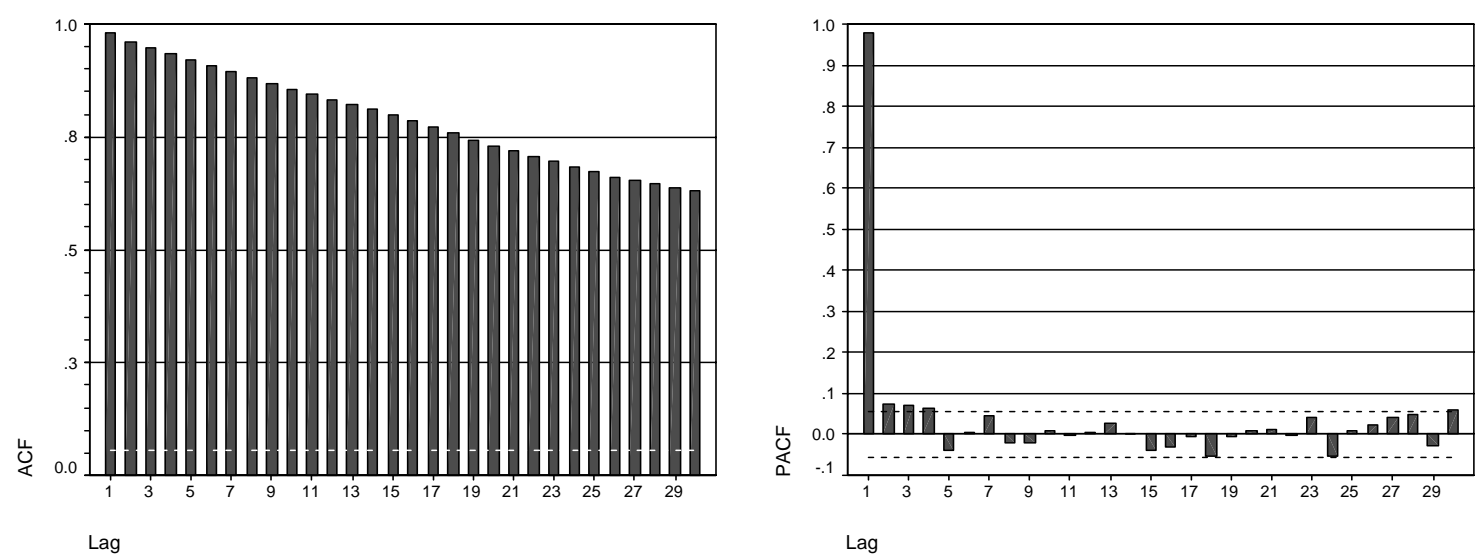

Figure 7: Autocorrelation (ACF) and partial autocorrelation function (PACF) for $S P^{*}$.

The autocorrelation $(\mathrm{ACF})$ and the partial autocorrelation function (PACF) can serve as indicators of whether a series is stationary. Figure 7 shows the ACF and PACF for $S P^{*}$ over the sample period from 1995 to 1999. The slow decay of ACF indicates either 
a large characteristic root, a unit root, or a trend stationary process (Enders, 1995, p. 211). Shocks to a unit root process are permanent so that the variance goes to infinity as time approaches infinity.

Applying the augmented Dickey-Fuller test to $S P^{*}$, we cannot reject the null hypothesis of a unit root on conventional significance levels. Yet as is well known, the available tests have low power to distinguish between unit root and near unit root processes (Enders, 1995, p. 261). Our failure to reject the null hypothesis does not suffice to draw the conclusion that a unit root exists. As far as $S P^{*}$ is concerned, economic theory does not support a unit root since the variable should be subject to an upper arbitrage bound even if severe violations of the Black-Scholes assumptions occur. Thus, we suppose that $S P^{*}$ follows a stationary process. Similar arguments hold for the explanatory variables.

The $S P^{*}$ time series exhibits partial autocorrelations of lags 2, 3 and 4 which are significantly positive, though small in absolute values. ${ }^{30}$ Therefore, the variable might be modelled by an $\mathrm{AR}(1)$ process,

$$
S P_{t}^{*}=a_{0}+a_{1} S P_{t-1}^{*}+\varepsilon_{t}, \quad\left|a_{1}\right|<1
$$

Estimates of the autocorrelation coefficient $a_{1}$ are given in Table 2 (standard errors are in parentheses). In the total period and two subperiods of approximately equal size the coefficient exceeds 0.96 . The optimal $s$-days-ahead forcast $\overline{S P}_{t+s}^{*}$ for the stationary $\mathrm{AR}(1)$ process (14) conditional on $S P_{t}^{*}, S P_{t-1}^{*}, \ldots$ is given by (see, e.g., Hamilton, 1994, p. 80):

$$
\overline{S P}_{t+s}^{*}=c+a_{1}^{s}\left(S P_{t}^{*}-c\right)
$$

where

$$
c=\frac{a_{0}}{\left(1-a_{1}\right)}
$$

The estimates of the coefficient $c$ are shown in Table $2 .{ }^{31}$ They illustrate that the level of $S P^{*}$-values increased from the first to the second subperiod. All in all, the estimated coefficients of the assumed $\operatorname{AR}(1)$ model seem sufficiently stable so as to allow the conclusion that past estimates of an $\operatorname{AR}(1)$ model are useful in predicting $S P^{*}$ on the next day.

\footnotetext{
$\overline{30}$ For example, the sample partial autocorrelation of lag 2 for 1995 to 1999 is 0.074 with a standard error of 0.029 .

31 The values were exactly calculated and then rounded to 4 digits.
} 


\begin{tabular}{|l|c|r|r|}
\hline & $\mathbf{1 9 9 5 - 9 9}$ & $\mathbf{1 9 9 5 - 0 6 / 9 7}$ & $\mathbf{0 6 / 9 7 - 1 9 9 9}$ \\
\hline$\widehat{a}_{0}$ & 0.0008 & 0.0009 & 0.0017 \\
\hline \multirow{2}{*}{$\widehat{a}_{1}$} & 0.9812 & 0.9736 & 0.9673 \\
& $(0.029)$ & $(0.040)$ & $(0.041)$ \\
\hline$\widehat{c}$ & 0.0434 & 0.0349 & 0.0512 \\
\hline
\end{tabular}

Table 2: Estimated coefficients of a stationary AR(1) process for SP*.

\subsection{Estimation Method}

The observation of significant correlations in the time series of $S P^{*}$ does not in itself reveal which fundamentals determine the smile pattern. Detecting these fundamentals is important to understand the economic rationale underlying the time series behaviour of the smile pattern. We postulate that $S P^{*}$ linearly depends on the variables defined in Section 5.1, and a random disturbance $\varepsilon$ :

$$
S P_{t}^{*}=\alpha_{0}+\sum_{i=1}^{11} \alpha_{i} X_{i t}+\varepsilon_{t}
$$

where $\alpha_{i}(i=0, \ldots, 10)$ are regression coefficients and $X_{i}$ is the $i$ th element of the set of variables $\{V O L M N, S K M N, K T M N, V O L 33, S K 33, K T 33, V V O L, J U M P, D A X R T$, $C O R R, P V O T M P\}$. Equation (15) formulates a purely explanatory model. The relationship is obviously inappropriate for analyzing the predictive power of the chosen variables, because their contemporaneous values are included without a lag.

Estimating regressions according to Equation (15) for the total time period from 1995 to 1999 yields highly correlated residuals. When the disturbance is autoregressive, the least squares estimators of the regression coefficients are inefficient and their estimated variances are biased.

One common method of handling serially correlated disturbances is to model them by a stationary $\mathrm{AR}(1)$ process and to compute generalized least squares estimators. ${ }^{32}$ Following this direction we carry out the iterative Cochrane-Orcutt transformation (see,

\footnotetext{
32 An alternative to resolving the problem of serially correlated disturbances is to add lagged values of the independent variables to the regression model. In principle this approach seems preferable to a generalized least squares estimation such as the Cochrance-Orcutt transformation, since it aims at improving the specification of an incomplete regression model (Granger/Hyung/Jeon, 1998). This approach, however, gives rise to the difficulty that the number of explanatory variables increases considerably, and the regressors may exhibit a high degree of multicollinearity (Theil, 1971, p. 259).
} 
e.g., Kmenta, 1997, p. 314), which consists of successive applications of the ordinary least squares method. ${ }^{33}$

\subsection{Empirical Results}

The empirical results are summarized in the first three columns of Table 3 , where $\widehat{\rho}_{e}$ denotes the autocorrelation of the residuals in the last iteration of the Cochrane-Orcutt procedure. $^{34}$ These coefficients are used to transform the dependent and independent variables. $R_{a d j}^{2}$ is the adjusted coefficient of determination. The regression slopes are reported as standardized coefficients with the corresponding t-statistics attached in parentheses.

The estimated residual autocorrelation coefficients $\hat{\rho}_{e}$ are much higher than the values obtained in the first step. Using these without further iterations is known as the Cochrane-Orcutt two-step method (see, e.g., Kmenta, 1997, p. 315). The higher values of $\hat{\rho}_{e}$ are partly due to the fact that $\hat{\rho}$ is obtained from a spurious regression, which falsely assigns a large part of the autocorrelation in the disturbances to the spurious relationship between the explanatory variables and $S P^{*}$. Thus, the true autoregressive parameter $\rho$ is underestimated. In our study this method would yield markedly higher coefficients of determination than reported in Table $3 .{ }^{35}$ The iterative Cochrane-Orcutt method applied in this study leads to autoregression estimates of about 0.97 , depending on the sample period. When the autoregression coefficient approaches unity, the iterative Cochrane-Orcutt procedure is asymptotically equivalent to differencing the data before estimating the relation (Hamilton, 1994, p. 562). Therefore, these two approaches to avoid spurious regressions are similar in our context. ${ }^{36}$

To analyze the stability of the regression coefficients, we as before subdivide the sample period into two subperiods. The results reveal that at most $4.5 \%$ of the variation of the transformed variable $S P^{*}$ can be attributed to the variation of the transformed

\footnotetext{
33 In related work this method is, e.g., applied by Longstaff (1995).

34 The iterations are repeated until the change in $\rho$ is lower than 0.001 .

35 Harvey (1990) notes: "The Cochrane-Orcutt iterative procedure [...] implies no improvement as far as asymptotic properties are concerned, although it may have a significant effect in small samples." (p. 194).

36 Differencing the data is usually "not recommended unless it is really believed that $\rho$ is very close to unity" (Kmenta, 1997, p. 322; see also Hamilton, 1994, p. 562).
} 


\begin{tabular}{|c|c|c|c|c|}
\hline & 1995-06/97 & 06/97-1999 & 1995-99 & 1995-99 \\
\hline Method & $\mathrm{CO}$ & $\mathrm{CO}$ & $\mathrm{CO}$ & NW \\
\hline$\widehat{\rho}_{e}$ & 0.969 & 0.968 & 0.982 & - \\
\hline$R_{a d j}^{2}($ in $\%)$ & 4.5 & 3.7 & 2.6 & 41.1 \\
\hline F statistic & $2.67^{* *}$ & $3.07^{* *}$ & $3.98^{* *}$ & - \\
\hline$\widehat{\alpha}_{1}[V O L M N]$ & $\begin{array}{l}-0.120^{*} \\
(-2.51)\end{array}$ & $\begin{array}{l}-0.080 \\
(-1.70)\end{array}$ & $\begin{array}{c}-0.086^{* *} \\
(-2.64)\end{array}$ & $\begin{array}{l}-0.052 \\
(-0.80)\end{array}$ \\
\hline$\widehat{\alpha}_{2}[S K M N]$ & $\begin{array}{l}-0.038 \\
(-0.86)\end{array}$ & $\begin{array}{c}0.173^{* *} \\
(3.80)\end{array}$ & $\begin{array}{c}0.084^{* *} \\
(2.73)\end{array}$ & $\begin{array}{l}0.037 \\
(1.49)\end{array}$ \\
\hline$\widehat{\alpha}_{3}[K T M N]$ & $\begin{array}{l}0.041 \\
(0.89)\end{array}$ & $\begin{array}{l}0.064 \\
(1.39)\end{array}$ & $\begin{array}{l}0.050 \\
(1.60)\end{array}$ & $\begin{array}{l}0.028 \\
(0.99)\end{array}$ \\
\hline$\widehat{\alpha}_{4}[V O L 33]$ & $\begin{array}{l}-0.037 \\
(-0.85)\end{array}$ & $\begin{array}{l}-0.055 \\
(-1.26)\end{array}$ & $\begin{array}{l}-0.037 \\
(-1.24)\end{array}$ & $\begin{array}{c}0.238^{* *} \\
(3.81)\end{array}$ \\
\hline$\widehat{\alpha}_{5}[S K 33]$ & $\begin{array}{l}0.017 \\
(0.30)\end{array}$ & $\begin{array}{l}0.006 \\
(0.14)\end{array}$ & $\begin{array}{l}0.021 \\
(0.60)\end{array}$ & $\begin{array}{l}-0.027 \\
(-0.51)\end{array}$ \\
\hline$\widehat{\alpha}_{6}[K T 33]$ & $\begin{array}{l}-0.023 \\
(-0.43)\end{array}$ & $\begin{array}{l}-0.017 \\
(-0.39)\end{array}$ & $\begin{array}{l}-0.013 \\
(-0.37)\end{array}$ & $\begin{array}{c}-0.160^{* *} \\
(-3.26)\end{array}$ \\
\hline$\widehat{\alpha}_{7}[V V O L]$ & $\begin{array}{l}0.068 \\
(1.71)\end{array}$ & $\begin{array}{l}0.110^{*} \\
(2.52)\end{array}$ & $\begin{array}{c}0.077^{* *} \\
(2.63)\end{array}$ & $\begin{array}{l}0.121^{*} \\
(2.28)\end{array}$ \\
\hline$\widehat{\alpha}_{8}[J U M P]$ & $\begin{array}{l}0.066 \\
(1.39) \\
\end{array}$ & $\begin{array}{l}0.079 \\
(1.60) \\
\end{array}$ & $\begin{array}{l}0.079^{*} \\
(2.38)\end{array}$ & $\begin{array}{l}-0.005 \\
(-0.21)\end{array}$ \\
\hline$\widehat{\alpha}_{9}[D A X R T]$ & $\begin{array}{l}0.063 \\
(1.20)\end{array}$ & $\begin{array}{l}-0.089 \\
(-1.73)\end{array}$ & $\begin{array}{l}-0.043 \\
(-1.21)\end{array}$ & $\begin{array}{l}0.027 \\
(0.92)\end{array}$ \\
\hline$\widehat{\alpha}_{10}[C O R R]$ & $\begin{array}{l}0.090^{*} \\
(2.10)\end{array}$ & $\begin{array}{l}0.023 \\
(0.51)\end{array}$ & $\begin{array}{l}0.044 \\
(1.41)\end{array}$ & $\begin{array}{l}-0.106 \\
(-1.78)\end{array}$ \\
\hline$\widehat{\alpha}_{11}[P V O T M P]$ & $\begin{array}{c}0.119^{* *} \\
(2.95)\end{array}$ & $\begin{array}{r}0.047 \\
(1.14) \\
\end{array}$ & $\begin{array}{c}0.076^{* *} \\
(2.64)\end{array}$ & $\begin{array}{c}0.366^{* *} \\
(6.92)\end{array}$ \\
\hline \multicolumn{5}{|c|}{$*(* *):$ significant on the $5 \%(1 \%)$ level } \\
\hline
\end{tabular}

Table 3: Determinants of the smile pattern: Empirical results. 'CO' stands for CochraneOrcutt, 'NW' for Newey-West. 
explanatory variables. The hypothesis that none of the independent variables has an influence on $S P^{*}$ is rejected on the $1 \%$ significance level in all three periods. Estimated over the complete sample period, the coefficients of the variables $V O L M N, S K M N$, VVOL, JUMP and PVOTMP are significantly different from zero at least on the $5 \%$ level. Yet, only two of these coefficients have the predicted sign: strongly varying intraday volatilities in the index level of the recent past, measured by $V V O L$, seemingly reflect great uncertainty of market participants and a rather high probability of a sharp stock market decrease. Besides, the positive relation between PVOTMP and $S P^{*}$ is consistent with the hypothesis that a high demand for out-of-the-money puts pushes option prices, since market makers cannot easily neutralize the risk exposure from short put positions. This finding corresponds to the importance of transaction costs and liquidity effects for the pricing of index options earlier reported by Longstaff (1995) for the US and Pena/Rubio/Serna (1999) for the Spanish stock market.

The signs of the other significantly positive slope coefficients contradict our expectations. Ceteris paribus, the span of implied volatilities $S P^{*}$ seems to be augmented by a low intraday volatility $(V O L M N)$, a positive skewness $(S K M N)$, and a high overnight return $(J U M P)$. Especially the negative relation between $V O L M N$ and $S P^{*}$ is incompatible with the wide-spread view that the smile pattern gets steeper when intraday returns are excessively volatile. Our results, which do not reflect this experience, might have to do with the interrelation of $V O L M N$ with $V V O L$ apparent from the definition of $V V O L$ (see Section 5.1). If we tried to find an economic rationale for the seemingly positive influence of the skewness $S K M N$ on $S P^{*}$, we could argue that market participants' expectations might be contrary to the currently realized returns. This reasoning clearly illustrates that it is extremely difficult to find suitable measures for an important explanatory variable: the perceptions of the market participants implied in option prices.

In a recent related study, Pena/Rubio/Serna (1999) generate a time series of daily parameters describing the contemporaneous smile profile on the Spanish index options market. In a second step these parameters are attributed to a set of explanatory variables via regression analysis. Although it is certainly impossible to directly compare test statistics of both studies, the reported $R^{2}$ of 0.23 at the Spanish market ${ }^{37}$ seems to indicate a stronger relationship between explanatory and dependent variables than observed in Germany.

$\overline{37 \text { See Pena/Rubio/Serna (1999), p. } 1169 .}$. 
However, Pena/Rubio/Serna (1999) use a different method to account for autoregressive disturbances, which is based on the Generalized Method of Moments (Hansen, 1982). The authors first apply the ordinary least squares method to Equation (15) to obtain unbiased and consistent estimates of the slope coefficients. In order to overcome the problem of biased standard errors in the presence of autoregressive disturbances, the objective is then to find an appropriate estimator for the asymptotic covariance matrix of the estimated coefficients. Newey/West (1987) have devised such an autocorrelation consistent estimator (see, e.g., Greene, 1997, p. 506; Campbell/Lo/MacKinlay, 1997, p. $534)$.

The results of applying this method to our total sample period yields the estimates presented in the last column of Table 3 with "t ratios" based on Newey-West consistent standard errors. ${ }^{38}$ Obviously, the estimates strongly differ from the outcomes of the Cochrane-Orcutt method. The only coincidences of "significant" coefficients occurs for the variables $V V O L$ and $P V O T M P$. Not surpringly, the adjusted $R^{2}$ rises sharply.

The Newey-West estimation does not necessitate the specification of the structure of the variance-covariance matrix $\Omega$ of the disturbances. If the structure of $\Omega$ is known, this information is not explicitly used to improve the estimation. In such a situation it is often preferable to use sample information to estimate $\Omega$ and to apply the generalized least squares method. Since our results clearly indicate that the disturbances can be modelled by a stationary $\mathrm{AR}(1)$ process, the Cochrane-Orcutt procedure seems more appropriate. In this view, the extremely high t-statistic of the coefficient $\widehat{\alpha}_{10}$ when using Newey-West standard errors indicates, at least partly, a spurious relationship. It seems safe to conclude that the choice of an appropriate method to account for autoregression is crucial in any attempt to explain the time series behaviour of patterns in implied volatilities.

\section{Summary and Conclusions}

This paper deals with strike price biases in the pricing of German DAX options relative to the Black-Scholes model. To compute implied volatilities it is crucial to use synchronized

\footnotetext{
38 To apply the Newey-West estimator, the maximum lag length that receives a nonzero weight has to be determined in advance. We follow the proposal of Newey/West (1987) to determine this lag length and obtain a value of 6 .
} 
prices of the option and the underlying asset. We achieve this by properly matching transaction data for the DAX option and future. The current index level is distorted by tax effects of dividend payments. We solve this problem by deriving a market implied correction of the underlying prices which has not yet been presented in the literature.

Using all call and put prices of each trading day in the sample period from 1995 to 1999, we estimate the smile profile via regression analysis. The smile profile turns out to be asymmetric. Therefore, a quadratic regression is not applicable. For this matter, we formulate a spline regression model with two segments and apply the weighted least squares method. The results show a very accurate fit to the data. On average, the variation of moneyness, which is defined as the ratio of strike to futures price, explains about $95 \%$ of the cross-sectional variation of implied volatilities.

The vast majority of all smile patterns appear as a skew. Typically, implied volatilities decrease monotonically with increasing moneyness beyond at-the-money until, at the right border, the function rises slightly. The time-series of at-the-money implied volatilities obtained from our regression model is almost perfectly correlated with the German DAX volatility index, VDAX. We condense the daily smile information in two readily interpretable measures: the differences between the implied volatilities for degrees of moneyness of 0.95 and 1.0, as well as 1.0 and 1.05, respectively. These "spans" are highly correlated in accordance with the observation of a prevailing skew pattern. On average, an increase in moneyness by 0.1 corresponds to a decrease of implied volatilities by 4.2 percentage points. This decrease tends to rise in the sample period. It is an important result of this paper that the span of in-the-money and out-of-the-money implied volatilities can be modelled very precisely by an $\mathrm{AR}(1)$ process. The autocorrelation coefficient exceeds 0.98 throughout the sample period and amounts to approximately 0.97 in two subperiods. This means that the smile pattern "has a long memory" in the sense that shocks die out slowly.

In the second part of the paper we define proxy variables for the possible theoretical explanations of the smile pattern. The most important explanations refer to time-varying volatility, jumps, and market frictions. To account for serially correlated disturbances in our time-series regression we employ the iterative Cochrane-Orcutt transformation. An alternative method proposed by Newey-West seems to be subject to spurious regression in our context. This is why it is difficult to compare our study with recently published results of Pena/Rubio/Serna (1999) for the Spanish market. Although the F-statistic is significant on the $1 \%$ level for the sample period and both subperiods, the proportion of 
changes of the smile pattern explained by changes of our explanatory variables is small in absolute values. The proxies for volatility of volatility and the percentage trading volume of out-of-the-money puts seem to exert a significant positive influence on the degree of skewness in implied volatilities, as expected by theory. The other influences are either neglegible or difficult to interpret.

All in all, though the smile pattern can be estimated with great precision, our attempt to uncover the economic variables underlying the dynamics of the smile was not fully successful. This might indicate that the smile is driven by market sentiment rather than economic fundamentals. This seems to be a promising issue for further research.

\section{Bibliography}

Alexander, C. (2000): Principal Component Analysis of Implied Volatility Smiles and Skews, Discussion Papers in Finance 2000-10, ISMA Centre University of Reading. Andersen, L./Andreasen, J. (1999): Jump-Diffusion Processes: Volatility Smile Fitting and Numerical Methods for Pricing, Working Paper, General Re Financial Products.

Andersen, L./Brotherton-Ratcliffe, R. (1998): The Equity Option Volatility Smile: a Finite Difference Approach, in: Journal of Computational Finance, Vol. 1, No. 2, pp. 5-38.

Andersen, T. et al. (1999): The Distribution of Exchange Rate Volatility, Working Paper, National Bureau of Economic Research.

Ané, T./Geman, H. (1999): Stochastic volatility and transaction time: an activitybased volatility estimator, in: Journal of Risk, Vol. 2, No. 1, 1999, pp. 57-69.

Bates, D.S. (1996): Dollar jump fears, 1984-1992: Distributional abnormalities implicit in currency futures options, in: Journal of International Money and Finance, Vol. 15, pp. 65-93.

Black, F. (1976): The Pricing of Commodity Contracts, in: Journal of Financial Economics, Vol. 3, pp. 167-179. 
Black, F./Scholes,M. (1973): The Pricing of Options and Corporate Liabilities, in: Journal of Political Economy, Vol. 81, pp. 637-659.

Breeden, D.T./Litzenberger, R.H. (1978): Prices of State-contingent Claims Implicit in Options Prices, in: Journal of Business, Vol. 51, pp. 621-651.

Campbell, J./Lo, A./MacKinlay, A. (1997): The Econometrics of Financial Markets, Princeton, New Jersey.

Chriss, N. (1996): Transatlantic Trees, in: Risk, Vol. 9, July, pp. 45-48.

Cochrane, J.H./Saá-Requejo (1996): Beyond Arbitrage: "Good-Deal" Asset Price Bounds in Incomplete Markets, Working Paper, University of Chicago.

Constantinides, G.M. (1996): Transactions Costs and the Implied Volatility Smile, Working Paper, University of Chicago.

Das, S./Sundaram, R. (1999): Of Smiles and Smirks: A Term-Structure Perspective, Working Paper, Harvard Business School.

Demeterfi, K. et al. (1999): More Than You Ever Wanted to Know About Volatility Swaps, Quantitative Strategies Research Notes, Goldman Sachs.

Derman, E. (1999): Regimes of Volatility, in: Risk, Vol. 12, April 1999, pp. 55-59.

Derman, E./Kani, I. (1994a): The Volatility Smile and Its Implied Tree, Quantitative Strategies Research Notes, Goldman Sachs.

Derman, E./Kani, I. (1994b): Riding on the Smile, in: Risk, Vol. 7, pp. 18-20.

Deutsche Börse (1997): Guide to the Volatility Indices of Deutsche Börse, Version 1.2, Frankfurt am Main.

Deutsche Börse (1999a): Guideline to Deutsche Börse's Equity Indices, Frankfurt am Main.

Deutsche Börse (1999b): Eurex Statistics 1999, Frankfurt am Main.

Deutsche Börse (2000a): About Eurex, www.eurexchange.com/entrancehall/welcome. html, Frankfurt am Main.

Deutsche Börse (2000b): Eurex Products - January 2000, Frankfurt am Main. 
Dumas, B./Fleming, J./Whaley, R.E. (1998): Implied Volatility Functions: Empirical Tests, in: Journal of Finance, Vol. 53, No. 6, pp. 2059-2106.

Dupire, B. (1994): Pricing With a Smile, in Risk, Vol. 7, January, pp. 18-20.

Eberlein, E./Keller, U./Prause, K. (1998): New insights into smile, mispricing and value at risk: the hyperbolic model, in: Journal of Business, Vol. 71, pp. 371-405.

Enders, W. (1995): Applied Econometric Time Series, New York et al.

Fengler, M.R./Härdle, W. (2000): The Dynamics of Implied Volatilities: A Common Principal Component Approach, Working Paper Humboldt Universität Berlin.

Figlewski, S. (1989a): Options Arbitrage in Imperfect Markets, in: Journal of Finance, Vol. 44, pp. 1289-1311.

Figlewski, S. (1989b): What Does an Option Pricing Model Tell Us About Option Prices, in: Financial Analysts Journal, Vol. 45, No. 5, pp. 12-15.

Figelwski, S./Wang, X (2000): Is the "Leverage Effect" a Leverage Effect?, Working Paper Stern School of Business, New York.

Galai, D. (1983): The Components of the Return From Hedging Options, in: Journal of Business, Vol. 56, pp. 45-54.

Gemmill, G. (1986): The forecasting performance of options prices, in: Journal of Business Finance and Accounting, Vol. 13, pp. 535-546.

Gemmill, G. (1993): Option pricing, London et al.

Granger, C./Hyung, N./Jeon, Y. (1998): Spurious regressions with stationary series, Discussion paper 98-25, University of California, San Diego.

Granger, C./Newbold, P. (1974): Spurious Regressions in Econometrics, in: Journal of Econometrics, Vol. 2, pp. 111-120.

Greene, W. (1997): Econometric Analysis, 3rd ed., Englewood Cliffs.

Hansen, L. (1982): Large Sample Properties of Generalized Method of Moments Estimators, in: Econometrica, Vol. 50, pp. 1029-1054.

Hamilton, J. (1994): Time Series Analysis, Princeton, New Jersey. 
Harvey, A. (1990): The Econometric Analysis of Time Series, 2nd ed., Cambridge, Mass.

Hermann, R. (1999): Nichtparametrische Optionsbewertung, Frankfurt/M. et al.

Heston, S. (1993): A Closed-Form Solution for Options with Stochastic Volatility with Applications to Bond and Currency Options, in: Review of Financial Studies, Vol. 6, pp. 327-344.

Heynen, R. (1994): An Empirical Investigation of Observed Smile Patterns, Working paper, Tinbergen Institute, Erasmus University, Rotterdam.

Hull, J. (1997): Options, Futures, and Other Derivative Securities, 3rd ed., Englewood Cliffs.

Hull, J./White, A. (1987): The Pricing of Options on Assets with Stochastic Volatilities, in: Journal of Finance, Vol. 42, pp. 281-300.

Jacquier, E. (1999): Volatility forecasting and modelling techniques, Risk Training Course, London.

Jackwerth, J. (1997): Generalized Binomial Trees, in: Journal of Derivatives, Vol. 5, No. 2, pp. 7-17.

Jackwerth, J./Rubinstein, M. (1995): Recovering Probability Distributions from Contemporaneous Security Prices, Working Paper, University of California at Berkeley.

Kemna, A. (1989): An empirical test of the option pricing model based upon transactions data of the European options exchange, in: Guimares, R. et al. (eds), A Reappraisal of Market Efficiency, Berlin/Heidelberg/New York.

Kmenta, J. (1997): Elements of Econometrics, 2nd ed., Michigan.

Longstaff, F. (1995): Option Pricing and the martingale restriction, in: Review of Financial Studies, Vol. 8, No. 4, pp. 1091-1124.

Maddala, G.S. (1988): Introduction to Econometrics, New York/London.

Mayhew, S. (1995): Implied Volatility, Financial Analysts Journal, July-August 1995, pp. 8-17.

McMillan, L. (1996): McMillan on Options, New York et al. 
Merton, R.C. (1976): Option pricing when underlying stock returns are discontinuous, in: Journal of Financial Economics, Vol. 3, pp. 124-144.

Natenberg, S. (1994): Option Volatility \& Pricing, Chicago/Cambridge.

Neumann, M./Schlag, C. (1996): Martingale Restrictions and Implied Distributions for German Stock Index Prices, Universität Karlsruhe, Diskussionspapier des Instituts für Entscheidungstheorie und Unternehmensforschung Nr. 196.

Newey, W./West, K. (1987): A Simple Positive Semi-Definite, Heteroscedasticity and Autocorrelation Consistent Covariance Matrix, in: Econometrica, Vol. 55, pp. 703-708.

Pena, I./Rubio, G./Serna, G. (1999): Why do we smile ? On the determinants of the implied volatility function, in: Journal of Banking \& Finance, Vol. 23, pp. 11511179 .

Ripper, K./Günzel, A. (1997): Volatilitäts-Smile von DAX-Optionen, in: Finanzmarkt und Portfolio Management, Vol. 11, No. 4, pp. 470-477.

Röder, K. (1994): Der DAX-Future - Bewertung und empirische Analyse, Bergisch Gladbach und Köln.

Rosenberg, J.V. (2000): Implied Volatility Functions: A Reprise, in: Journal of Derivatives, Vol. 7, No. 3, pp. 51-64.

Rubinstein, M. (1985): Non-parametric Tests of Alternative Option Pricing Models Using All Reported Trades and Quotes on the 30 most Active CBOE Option Classes from August 23, 1976 through August 31, 1978, in: Journal of Finance, Vol. 40, pp. 455-480.

Rubinstein, M. (1994): Implied Binomial Trees, in: Journal of Finance, Vol. 49, pp. 771-818.

Sachs, L. (1972): Statistische Auswertungsmethoden, 3rd ed., Berlin/Heidelberg/New York.

Sheikh, A. (1991): Transaction Data Tests of S\&P 100 Call Option Pricing, in: Journal of Financial and Quantitative Analysis, Vol. 26, pp. 727-752.

Skiadopoulos, G./Hodges, S./Clewlow, L. (1998): The Dynamics of Implied Volatility Surfaces, Working Paper, Financial Options Research Center Preprint 1998/86, 
University of Warwick, UK.

Stein, E./Stein, J. (1991): Stock Price Distributions with Stochastic Volatility: An analytical approach, in: Review of Financial Studies, Vol. 4, pp. 727-752.

Shimko, D. (1991): Beyond Implied Volatility: Probability Distributions and Hedge Ratios Implied by Option Prices, Working Paper, University of Southern California.

Shimko, D. (1993): Bounds of Probability, in: Risk, Vol. 6, No. 4, pp. 33-37.

Taleb, N. (1997): Dynamic Hedging, New York et al.

Theil, H. (1971): Principles of Econometrics, New York.

Tompkins, R.G. (1999): Implied Volatility Surfaces: Uncovering Regularities for Options on Financial Futures, Working Paper, Vienna University of Technology.

Trautmann, S./Beinert, M. (1999): Impact of Stock Price Jumps on Options Values, in: Bühler, W./Hax, H./Schmidt, R. (eds.): Empirical Research on German Capital Markets, Berlin et al.

Wilmott, P. (1998): Derivatives: The Theory and Practice of Financial Engineering, New York et al.

Zou, J./Derman, E. (1999): Strike-Adjusted Spread, Quantitative Strategies Research Notes, Goldman Sachs. 